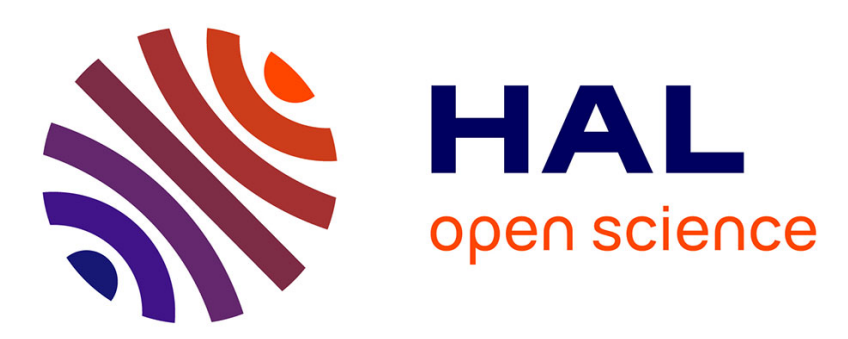

\title{
Computer search for layer materials that maximize the reflectivity of X-ray multilayers
}

\author{
A.E. Rosenbluth
}

\section{To cite this version:}

A.E. Rosenbluth. Computer search for layer materials that maximize the reflectivity of X-ray multilayers. Revue de Physique Appliquée, 1988, 23 (10), pp.1599-1621. 10.1051/rphysap:0198800230100159900 . jpa-00245990

\section{HAL Id: jpa-00245990 https://hal.science/jpa-00245990}

Submitted on 1 Jan 1988

HAL is a multi-disciplinary open access archive for the deposit and dissemination of scientific research documents, whether they are published or not. The documents may come from teaching and research institutions in France or abroad, or from public or private research centers.
L'archive ouverte pluridisciplinaire HAL, est destinée au dépôt et à la diffusion de documents scientifiques de niveau recherche, publiés ou non, émanant des établissements d'enseignement et de recherche français ou étrangers, des laboratoires publics ou privés. 


\title{
Computer search for layer materials that maximize the reflectivity of X-ray multilayers
}

\author{
A. E. Rosenbluth \\ Thomas J. Watson Research center, IBM Corporation, Yorktown Heights, NY 10598, U.S.A.
}

(Reçu le 26 octobre 1987, révisé le 15 janvier 1988, accepté le 5 février 1988)

\begin{abstract}
Résumé. - La réflectivité des miroirs multicouches est optimisée en sélectionnant des matériaux à l'aide d'une base de données de coefficients atomiques. Les performances maximum et les matériaux correspondants sont indiqués pour 63 longueurs d'onde espacées régulièrement sur une échelle logarithmique s'étendant de 6 à $124 \AA$. Des formules de calculs rapides permettant une telle sélection sont présentées. Un choix de plusieurs combinaisons de matériaux utilisables est indiqué en fonction de différents critères. Très fréquemment les couples de matériaux donnant la meilleure réflectivité au sommet du pic de Bragg fournissent aussi la meilleure réflectivité intégrée, mais certains couples n'optimisent qu'un des deux types de réflectivité.
\end{abstract}

\begin{abstract}
A database of atomic scattering factors [1] is exhaustively searched for layer materials that potentially maximize collection solid-angle in a multilayer mirror. Maximum attainable performance and corresponding materials are provided at 63 logarithmically spaced wavelengths in the soft X-ray region ( $6 \AA<\lambda<124 \AA$ ). Computationally rapid formulas that enable an efficient search are presented. Only a cursory screening is made of material suitability, but a number of possible materials combinations are provided at each wavelength, selected according to several different criteria. Materials-pairs which maximize peak reflectivity often provide high integrated reflectivity as well, but materials rankings by peak and integrated reflectivities show distinct differences.
\end{abstract}

\section{Introduction.}

Materials considerations have been crucial in the development of X-ray multilayer reflectors. Materials choices have been [2,3] and remain [4] a topic of interest in the X-ray multilayer literature. The related matter of multilayer performance and structural quality has been described as a dominant topic of the genre [5]. Analyses of the reflecting properties of multilayers have dealt with both idealized structures, and with various types of imperfections (see for example the contents and cited references in recent articles by Barbee [4], Henke et al. [6], and Spiller and Rosenbluth [7]).

In this paper we consider only the ideal case of high-index/low-index periodic multilayers that operate in the extinction limit (i.e. large number of layers). The analysis of Vinogradov and Zeldovich [8] then makes it possible to rapidly calculate the maximum reflectivity obtainable from a particular pair of materials at a given X-ray wavelength. Elaborating on previous work [9], we show how this analysis can be developed into approximate formulas for optimized integrated reflectivity, or collection solid angle in the case of a focussing reflector. It then becomes feasible to search efficiently through all possible pairs of multilayer materials, thereby establishing the upper limits of multilayer performance, and uncovering potentially useful materials.

\section{Computations.}

Using the notation of a previous publication [7] the results of Vinogradov and Zeldovich [8] imply the following simple form for-peak reflectivity :

$$
R_{\text {peak }}=\frac{4 R_{12} \sin ^{2} \gamma}{(A+B)^{2}}
$$


where $R_{12}$ is the reflectivity of a single high-low interface,

$$
\begin{array}{rlr}
R_{12}=\left|r_{12}\right|^{2} & =\left|\frac{n_{1} \cos \alpha_{1}-n_{2} \cos \alpha_{2}}{n_{1} \cos \alpha_{1}+n_{2} \cos \alpha_{2}}\right|^{2} & \text { (s-polarization) } \\
& \cong \frac{1}{4}\left(\left[n_{1}^{\prime}-n_{2}^{\prime}\right]^{2}+\left[n_{1}^{\prime \prime}-n_{2}^{\prime \prime}\right]^{2}\right) \sec ^{4} \alpha_{0} & \text { (s-polarization) } \\
& =\left|\frac{n_{1} \cos \alpha_{2}-n_{2} \cos \alpha_{1}}{n_{1} \cos \alpha_{2}+n_{2} \cos \alpha_{1}}\right|^{2} & \text { (p-polarization) } \\
\cong \frac{1}{4}\left(\left[n_{1}^{\prime}-n_{2}^{\prime}\right]^{2}+\left[n_{1}^{\prime \prime}-n_{2}^{\prime \prime}\right]^{2}\right) \cos ^{2}\left(2 \alpha_{0}\right) \sec ^{4} \alpha_{0} & \text { (p-polarization) }
\end{array}
$$

with primes and double-primes denoting real and imaginary parts, $n_{1}$ and $n_{2}$ the refractive indices of the two layer materials, and $\alpha_{0}, \alpha_{1}$ and $\alpha_{2}$ the angles of incidence and propagation in the incident and film media. $\gamma$ is a parameter in radian units which specifies the division of the multilayer unit period between the two materials ; $\gamma \equiv \pi d_{1} / p$, with $p \equiv$ $d_{1}+d_{2}$ the multilayer period. For simplicity, we let the subscript 1 denote the high index layer (in the sense of $n_{1}^{\prime \prime}>n_{2}^{\prime \prime}$ ), and subscript 2 the low index layer. The quantities $A$ and $B$ are defined as

$$
\begin{aligned}
A & \equiv \sqrt{\mu^{\prime \prime 2}+\left(2 r_{12}^{\prime} \sin \gamma\right)^{2}} \\
B & \equiv \sqrt{\mu^{\prime \prime 2}-\left(2 r_{12}^{\prime \prime} \sin \gamma\right)^{2}}
\end{aligned}
$$

where $\mu$ is the complex optical phase dispersion in propagating through the unit period [10],

$$
\begin{aligned}
& \mu\left(\alpha_{0}\right)=\frac{2 \pi}{\lambda} \times \\
& \quad \times\left(\left[\int_{\text {period }} \mathrm{d} z n(z) \cos \alpha(z)\right]-p \cos \alpha_{0}\right)
\end{aligned}
$$

with the local angle of refraction defined by $n(z) \sin \alpha(z) \equiv \sin \alpha_{0}$. In the X-ray regime

$$
\mu\left(\alpha_{0}\right) \cong \frac{2 p}{\lambda \cos \alpha_{0}}\left(\pi\left[n_{2}-1\right]+\gamma\left[n_{1}-n_{2}\right]\right) .
$$

Equation (1) is essentially a real expression for the peak intensity in a general complex Darwin-Prins solution, based on the assumption $\left(n_{1,2}-1\right) \sec ^{2} \alpha \ll 1$. This equation has the approximate form of a single-period reflection, multiplied by the square of the number of participating periods. Equations (1) and (6) as written assume ideal multilayer structures, having sharp layer boundaries.

The condition for maximizing $R_{\text {peak }}$ is

$$
\tan \gamma=\gamma+W
$$

(see Eq. (23) and associated discussion in Ref. [8]), where

$$
W \equiv \frac{\pi\left(n_{2}^{\prime \prime}-1\right)}{n_{1}^{\prime \prime}-n_{2}^{\prime \prime}} .
$$

Equation (7) can be solved iteratively with the formulas [9] :

$$
\begin{aligned}
\gamma_{0} & =\sqrt[3]{3 W-2.5\left(\frac{W}{1+W}\right)^{5 / 3}}, \\
\gamma_{i+1} & =\gamma_{i}-\frac{\tan \gamma_{i}-\gamma_{i}-W}{\sec ^{2} \gamma_{i}-1}, \quad(W<0.66) \\
\gamma_{0} & =\frac{1}{2}\left[\pi-\left(W+\frac{\pi}{2}\right)+\sqrt{\left(W+\frac{\pi}{2}\right)^{2}-4}\right] \\
\gamma_{i+1} & =\arctan \left(\gamma_{i}+W\right), \quad(W>0.66)
\end{aligned}
$$

In the soft $\mathrm{X}$-ray regime multiple reflections between the thin-films are often small, and the reflectivity as a function of Bragg detuning can be approximated with a Lorentzian [11] :

$$
R(\phi)=\frac{R_{12} \sin ^{2} \gamma}{\left(\phi-\mu^{\prime}\right)^{2}+\mu^{\prime \prime 2}},
$$

where

$$
\phi \equiv \pi-\frac{2 \pi p \cos \alpha_{0}}{\lambda}
$$

Here the parameter $\phi$ defines the detuning from the nominal Bragg resonance (taken for simplicity as first-order).

Equation (10) can be used to estimate the collec-

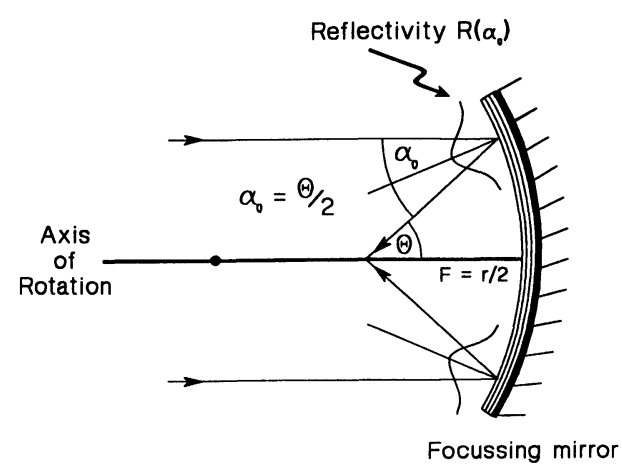

Fig. 1. - Schematic diagram of a focussing multilayer (with figured substrate). Collection solid-angle is maximized if the reflection peak is detuned slightly from normal incidence. 
tion solid angle of a multilayer focussing collimated radiation, as in figure 1 . (See also the detailed computational study in Ref. [12]). The estimate of $\boldsymbol{\Omega}_{\text {collection }}$ takes a particularly simple form when the $\alpha$-dependence can be neglected in all terms other than $\phi$. Such neglect is usually accurate in the X-ray regime, where significant reflectivity is achieved with many layers and a narrow bandpass; however the resulting expressions become less accurate in the soft X-ray regime. If we let $\alpha_{B}$ denote the nominal
Bragg angle (at which $\phi$ is zero), we have from figure 1 that

$$
\mathrm{d} \Omega=2 \pi \sin \Theta \mathrm{d} \Theta \cong 8 \pi \cos \alpha_{\mathrm{B}} \mathrm{d}(\cos \alpha),
$$

again assuming that terms varying as $\cos \alpha$ are effectively constant over the multilayer bandpass. (Note that, in contrast, terms varying as $\sin \alpha$ can only be treated as constant away from normal incidence.)

We then have :

$$
\begin{aligned}
\Omega_{\text {collection }} & \equiv \int R(\Omega) \mathrm{d} \Omega \\
& \cong 8 \pi R_{12}\left(\alpha_{\mathrm{B}}\right) \cos \alpha_{\mathrm{B}} \sin ^{2} \gamma \int_{0}^{1} \frac{\mathrm{d}(\cos \alpha)}{\left(\frac{2 \pi p}{\lambda}\right)^{2}\left(\left[\cos \alpha_{\mathrm{B}}-\mu^{\prime}\left(\alpha_{\mathrm{B}}\right)\right]-\cos \alpha\right)^{2}+\mu^{\prime \prime 2}\left(\alpha_{\mathrm{B}}\right)} .
\end{aligned}
$$

Equation (11) applies at all Bragg angles outside the grazing regime, including normal incidence, and can of course be integrated analytically. However, for simplicity we now assume that $\alpha_{B}$ is sufficiently far from $0^{\circ}$ that both sides of the reflectivity curve are realized at physical angles (i.e. $\geqslant 0^{\circ}$ ). Using $2 p \cos \alpha_{\mathrm{B}} \cong \lambda$, and considering the limiting case where the integral contains the full area of the Lorentzian :

$$
\begin{aligned}
\Omega_{\text {collection }} \leqslant & \frac{8 \pi \cos ^{3} \alpha_{\mathrm{B}}}{\pi^{2}} R_{12}\left(\alpha_{\mathrm{B}}\right) \sin ^{2} \gamma \times \\
& \times \frac{\pi}{\mu^{\prime \prime}\left(\alpha_{\mathrm{B}}\right) \frac{\lambda}{2 \pi p}} \\
& \cong 8 \pi R_{\text {peak }} \mu^{\prime \prime}\left(\alpha_{\mathrm{B}}=0\right) .
\end{aligned}
$$

This simple expression for $\Omega_{\text {collection }}$ has the form of a peak reflectivity, multiplied by a bandwidth and a trigonometric factor. Note that if the multilayer is tuned for a reflection peak at precise normal incidence, only about one-half the solid angle in equation (12) will be realized.

With s-polarization, $R_{\text {peak }} \mu^{\prime \prime}\left(\alpha_{\mathrm{B}}=0\right)$ is independent of $\alpha_{\mathrm{B}}$. With un-polarized radiation, $R_{\text {peak }}$ may be approximated as an average over both polarizations.

$\mu^{\prime \prime}\left(\alpha_{\mathrm{B}}=0\right)$ is the imaginary part of the complex phase thickness (at normal incidence), and is essentially the reciprocal of the absorption-limited number of participating layer pairs. The $\mu^{\prime \prime}$ in equation (12) thus neglects primary extinction, and so equation (12) often overstates the number of participating layers in highly reflecting structures. A more suitable upper limit on $\Omega_{\text {collection }}$ is obtained by replacing $\mu$ " with the extinction-limited number of layer pairs, which is the reciprocal of the imaginary part of the equivalent phase thickness $[9,10,13]$. Here equivalent phase thickness refers to the analytic reduction of a multilayer stack to a single equivalent layer (as here), or to a pair of equivalent layers [14]. In terms of the parameters $A$ and $B$ defined above, the imaginary part of the equivalent phase thickness for an X-ray multilayer can be written

$$
g_{\text {peak }}=\frac{A B}{\mu^{\prime \prime}\left(\alpha_{\mathrm{B}}\right)} \text {. }
$$

Note that unlike $\mu, g$ is polarization-dependent away from normal incidence.

We thus have as an approximate upper limit on collection solid-angle :

$$
\Omega_{\text {collection }} \leqslant \Omega_{\max } \equiv 8 \pi \frac{R_{\text {peak }}(\text { s-polarization })}{N\left(\alpha_{\mathrm{B}}=0\right)}
$$

where the effective number of participating periods is given by

$$
N \equiv \frac{1}{g_{\text {peak }}^{\prime \prime}}
$$

with $g_{\text {peak }}$ and $R_{\text {peak }}$ defined by equations $(1-6,13)$. These expressions essentially involve only real arithmetic.

In the $100 \mathrm{eV}$ range $N$ is often of order 10 for an optimized multilayer (with typical scaling $N \sim(h \nu)^{2}$, or, at short wavelengths where operation at normal incidence is infeasible, as $N \sim \cos ^{2}\left(\alpha_{\mathrm{B}}\right)$ ). Since $R\left(\alpha_{0}\right)$ is Lorentzian-like, it has very broad tails, particularly near normal incidence. However, $\Omega_{\text {collection }}$ approaches the limit in equation (14) only to the extent that the full two-sided resonance in $R(\alpha)$ is realized at angles sufficiently close to normal incidence that polarization effects can be 
neglected. In addition, use of $g_{\text {peak }}$ sometimes overstates collection solid-angle. We have found by numerical integration that in the $100 \mathrm{eV}$ range the collection solid angle actually approaches only about $50 \%$ of the limit in equation (14). The limit would in principle be approached more closely at shorter wavelengths, except that the reflection must be increasingly annular in order to maintain a reasonable period length.

The above figure of merit $8 \pi R_{\text {peak }} g_{\text {peak }}^{\prime \prime}$ can also be regarded as an approximate index for the onedimensional integral of reflectivity over angle, to within a different normalization constant :

$$
\begin{aligned}
R_{\text {integrated }} & \equiv \int R(\alpha) \mathrm{d} \alpha \\
& \cong \frac{2 R_{\text {peak }} g^{\prime \prime}\left(\alpha_{\mathrm{B}}=0\right)}{\sin 2 \alpha_{\mathrm{B}}} .
\end{aligned}
$$

Equations $(7,9)$ optimize peak rather than integrated reflectivity. To maximize integrated reflectivi- ty, we use numerical optimization from the starting value :

$$
\gamma_{0}=\frac{\pi}{2}-\frac{1}{(2 W+\pi)-\frac{2}{(2 W+\pi)}} .
$$

Equation (17) is obtained from equation (14) by setting $g_{\text {peak }}^{\prime \prime} \cong \mu^{\prime \prime}$, differentiating with respect to $\gamma$, and setting $\tan \gamma \cong\left(\frac{\pi}{2}-\gamma\right)^{-1}$

\section{Materials search.}

The results of a sort across all possible pairs of the natural elements is shown in table I (at the end of the paper). The sorting parameter used by the program is the quantity $\Omega_{\max }$ defined in equation (14), which is the entry in the table labelled SOLID ANGLE. The search program prints several different lists of materials for each wavelength. Figure 2 shows the detailed criteria on which the different lists are based.

\section{Explanation of Difierent Entries at Each Wavelength}

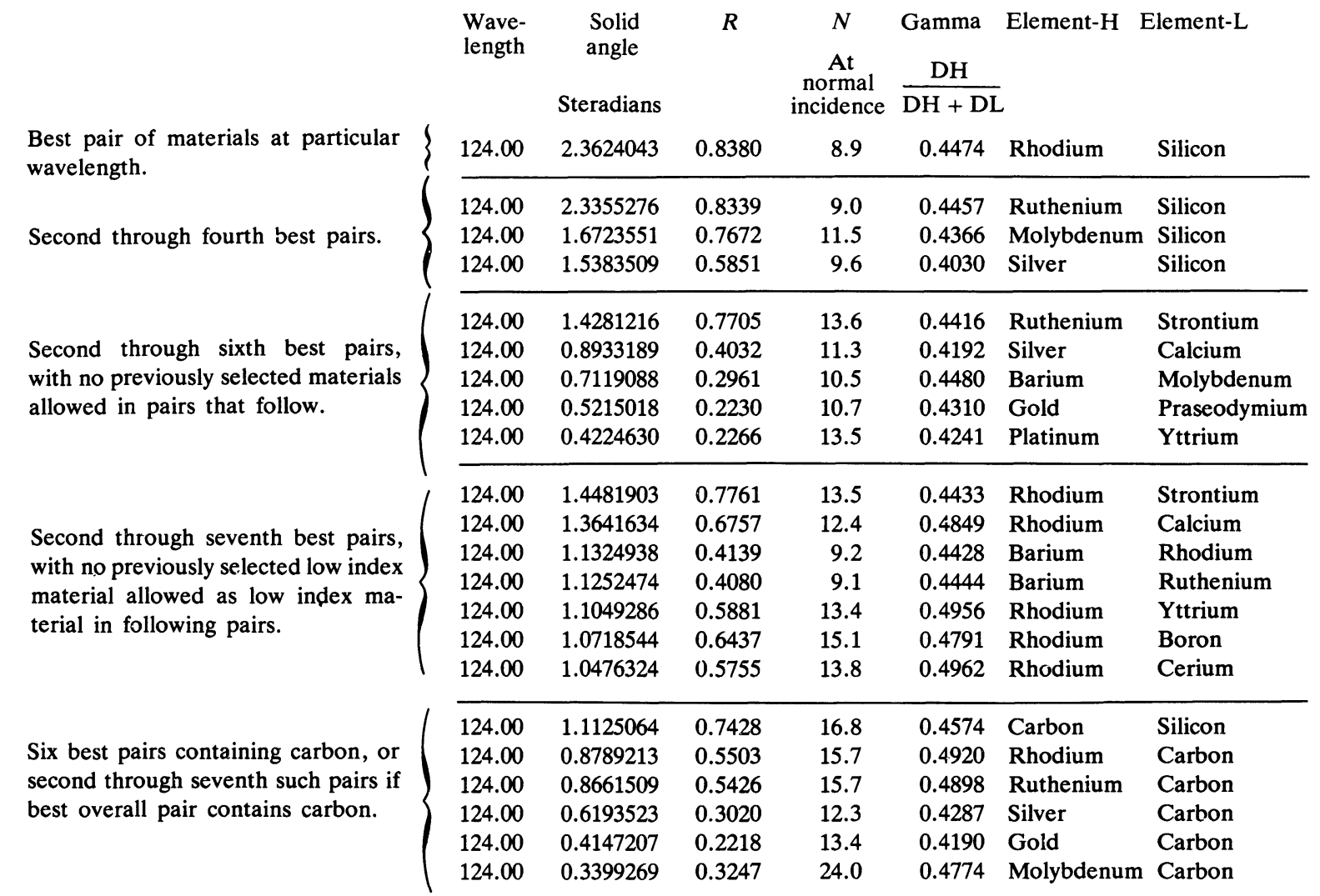

(By definition, the low index material in a pair is the material with the least absorption.)

Fig. 2. - Breakdown of the entries in table I. The sort by maximum $\Omega_{\text {collection }}$ is carried out under several different constraints, each resulting in a separate subgroup. 
The table also lists the peak reflectivity $(R)$, the $\gamma$ value that optimizes $\Omega_{\max }$, and the number of layer pairs $N$ required to approach this performance (as per Eq. (15)).

It must be emphasized that these results are purely theoretical. No effort has been made to assess the individual suitability or joint compatibility of the chosen materials, in terms of the quality or stability of either the layers or their interfaces. Bulk densities are assumed in the layers, which tends to overstate the integrated reflectivity. A crude materials screening has been imposed by the requirement that the elements considered have melting points above $270^{\circ}$ (i.e. above that of bismuth). Beryllium and all radioactive elements were excluded. (Unlike other toxic elements, beryllium would have been frequently selected by the search program had it been included, due to its low atomic number.)

Only elemental films have been considered in the search, whereas it is known that a crucial smoothening can sometimes be obtained by alloying two materials [15]. This an important consideration, since interfacial smoothness can be a dominant factor in determining overall reflectivity. Films with high electron-density are generally metallic, and in the single-element case are likely to show excessive grain-size.

However, to a reasonable approximation, the nominal performance obtained by alloying two elements that appear singly in the table can be estimated as a weighted average of the table entries, due to the weak atomic scattering in the X-ray regime. In other words, alloying might allow an evaporated film to approach more closely the ideal performance levels calculated in the table.

Table II (at the end of the paper) presents the result of a materials search to optimize peak reflectivity, based on equations $(1,7,9)$. Only the materials-pair that provides the highest nominal $R_{\text {peak }}$ is listed at each wavelength.

\section{Conclusions.}

Tables I and II suggest that continued expansion of the fabricators' art may yield multilayers with significantly higher performance than is commonly achieved at present.

Of course, there are many qualifications to be made about the results of an optimization study such as this. The results in the tables are at best suggestive, and indicative of the upper limits of multilayer performance, as established by the properties of available materials in nature. (In the latter regard, however, it should be noted that the search has not considered the use of beryllium or hydrocarbon films, nor such exotic possibilities as free-standing or partially-supported films. Collection solid-angle can also be increased by stepping or grading the $d$ spacing $[12,16]$.

Materials-pairs that yield high peak reflectivity tend to be among those that yield high integrated reflectivity (with some exceptions), but the theoretically attainable maximum reflectivity can sometimes be significantly increased when the structure and materials optimize peak rather than integrated reflectivity. This is often most pronounced where low absorption makes possible designs achieving large $R_{\text {peak }}$ via small $g_{\text {peak }}$.

The surprisingly high performances in the tables are generally associated with the low absorption and anomalous dispersion (especially $f_{1}<0$ ) that are present in the vicinity of atomic resonances (see also Ref. [17]); these edges have been conveniently tabulated by Henke et al. [1].

Of course, the optical constants data may well be less reliable in such regions ; this may be particularly true in the case of more exotic elements. Database searches of the present sort tend intrinsically to be biased in favor of less accurate data, where the error happens to improve the calculated performance. On the other hand, it is perhaps encouraging that systematically high performance is predicted from certain film materials over wide portions of the spectrum (e.g. osmium, iridium, rhodium, ruthenium, nickel, magnesium, as well as the more familiar tungsten, rhenium, carbon and boron). Many other materials are selected in more limited portions of the spectrum.

\section{Acknowledgments.}

The author very gratefully acknowledges many helpful discussions with Eberhard Spiller and Burt Henke. I am particularly grateful to Burt Henke for providing a machine-readable version of the data in reference [1]. 


\section{References}

[1] HENKE, B. L. et al., Low-Energy X-Ray Interaction Coefficients : Photoabsorption, Scattering, and Reflection, At. Data Nucl. Data Tables 27 (1982) 1-144.

[2] SPILLER, Eberhard, Reflecting Multilayer Coatings for the Far-UV Range, Appl. Opt. 15 (1976) 2333-2338.

[3] Barbee, T. W., Sputtered Layered Synthetic Microstructure (LSM) Dispersion Elements, Low-Energy X-Ray Diagnostics, Eds. D. T. Attwood and B. L. Henke 75 (1982) 131-145.

[4] Barbee, T. W., Multilayers for X-Ray Optics, Opt. Eng. 25 (1986) 898-915.

[5] Perkins, R. T. et al., Theoretical Considerations in the Design of Multilayer X-Ray Optics, X-Ray Imaging II, Eds. L. V. Knight and D. K. Bowen 691 (1986) 76-82.

[6] Henke, B. L. et al., Characterization of Multilayer $\mathrm{X}$-Ray Analysers : Models and Measurements, Opt. Eng. 25 (1986) 937-947.

[7] Spiller, E., Rosenbluth, A. E., Determination of Thickness Errors and Boundary Roughness from the Measured Performance of a Multilayer Coating, Opt. Eng. 25 (1986) 954-963.

[8] Vinogradov, A. V., Ya Zeldovich, B., X-Ray and Far-UV Multilayer Mirrors : Principles and Possibilities, Appl. Opt. 16 (1977) 89-93.

[9] Rosenbluth, A. E., Ph. D. thesis, University of Rochester (University Microfilms) 1982.
[10] Rosenbluth, A. E. and Lee, P., Bragg Condition in Absorbing Multilayers, Appl. Phys. Lett. 40 (1982) 466-468.

[11] Henke, B. L., Low Energy X-Ray Spectroscopy with Crystals and Multilayers, Low-Energy X-Ray Diagnostics Eds. D. T. Attwood and B. L. Henke 75 (1982) 85-96.

[12] LEE, Ping, Uniform and Graded Multilayers as XRay Optical Elements, Appl. Opt. 22 (1983) 1241-1246.

[13] Rosenbluth, A. E., Forsyth, J. M., The Reflecting Properties of Soft X-Ray Multilayers, Low-Energy $X$-Ray Diagnostics Eds. D. T. Attwood and B. L. Henke 75 (1982) 280-285.

[14] Herpin, A., C. R. 225 (1947) 182.

[15] Haelbich, R. P. et al., Smooth Multilayer Films Suitable for X-Ray Mirrors, Appl. Phys. Lett. 34 (3) (1979) 184-186.

[16] Bruijn, M. P. et al., Automatic Electron-Beam Deposition of Multilayer Soft X-Ray Coatings with Laterally Graded d-Spacing, Opt. Eng. 25 (1986) 916-921.

[17] MARMORET, R., ANDRÉ, J. M., Bragg Reflectivity of Layered Synthetic Microstructures in the X-Ray Anomalous Scattering Regions, Appl. Opt. 22 (1983) 17-19. 

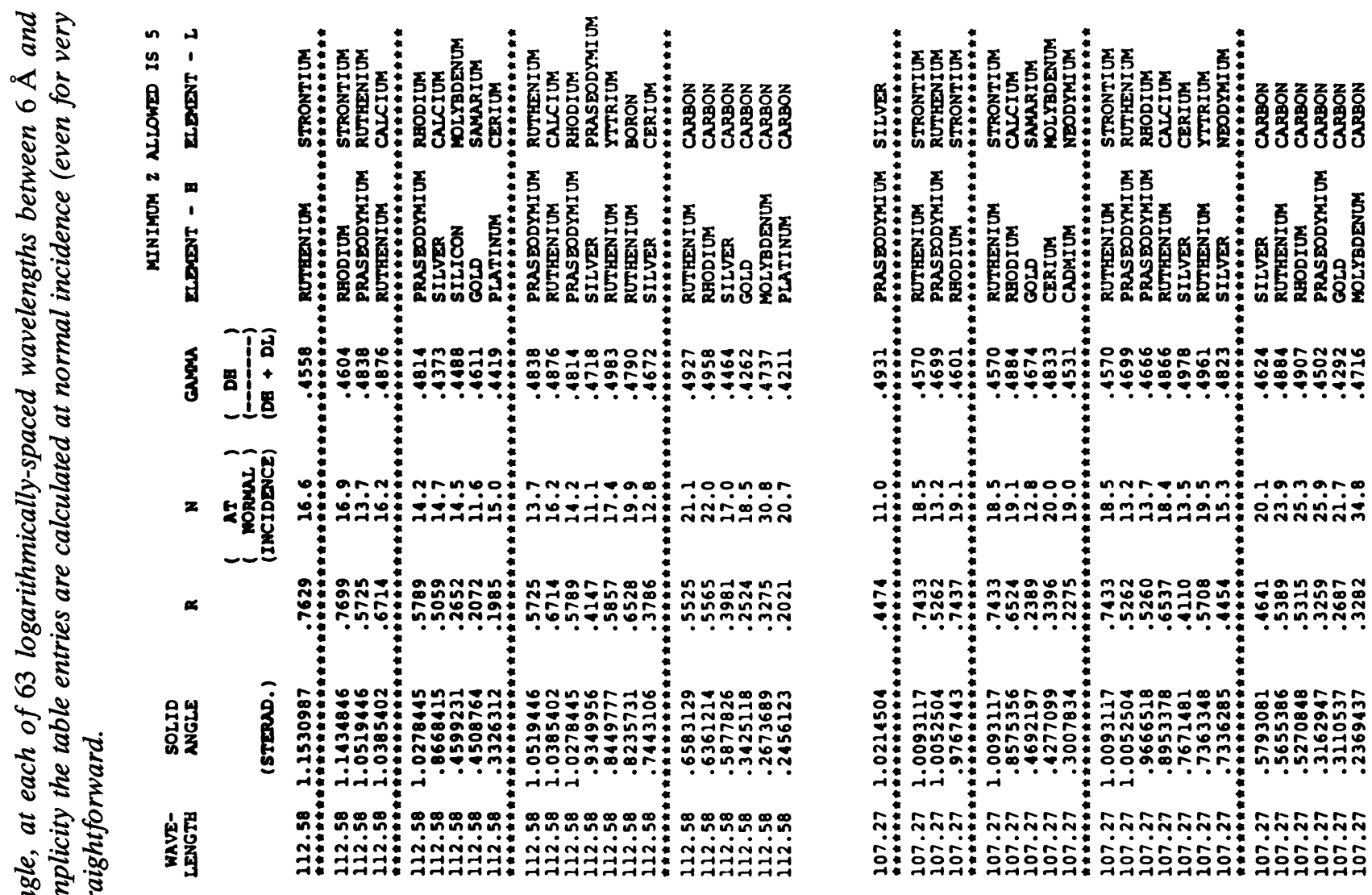

S

竞

क

ปัँ

胥

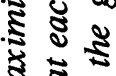

¿ $2 \frac{1}{8}$

2 0 :

20

के के

ई टे है

品家

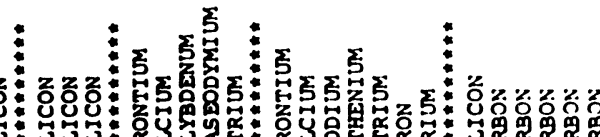

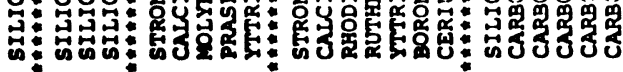

$\frac{0}{2} \frac{2}{\frac{1}{2}}$

क 50

ล.

辛 $\frac{2}{2}$

.5 $\frac{1}{2}$

के है है

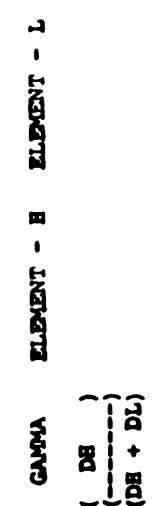

(

疋

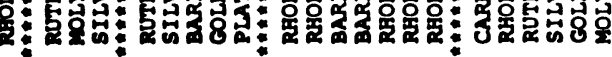

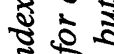

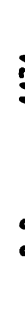

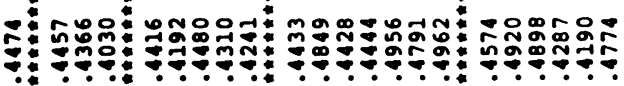

ก

竞 $\frac{20}{20}$

近

\& \& हे

$0 \circ \dot{1}$

常孛

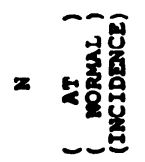

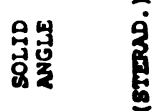

. 政

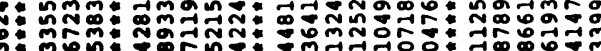

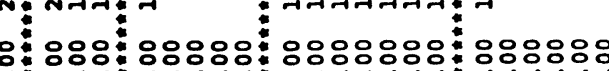

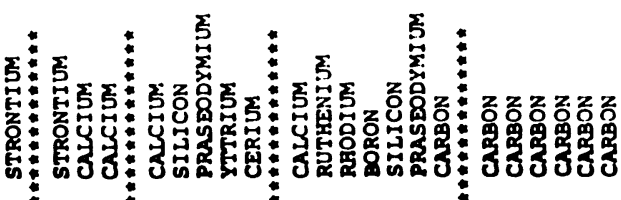

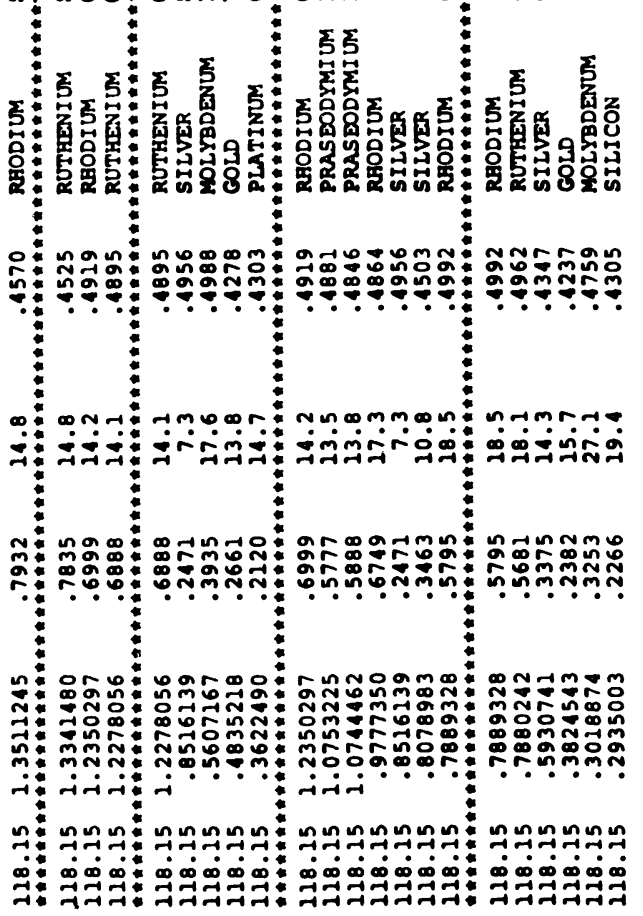




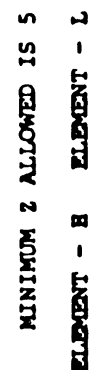

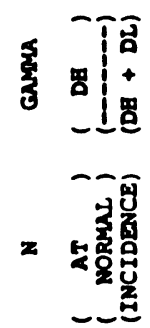

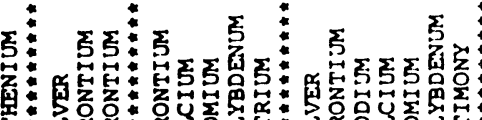

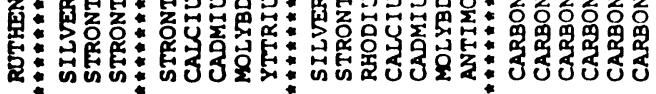

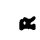

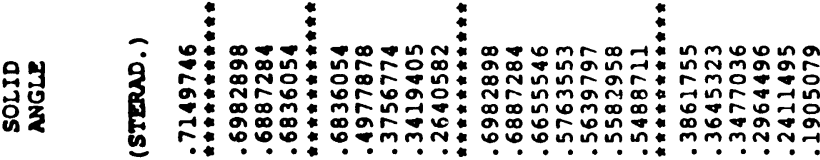

1:

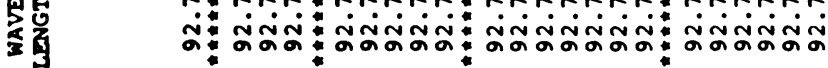

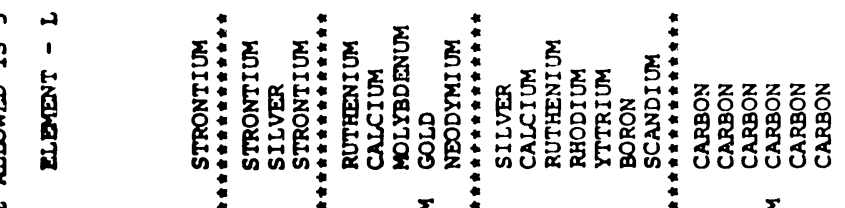

足

ง

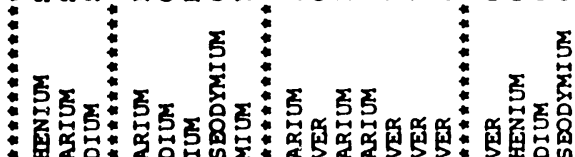

至

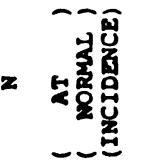

ํㅜㅇ

$\infty$

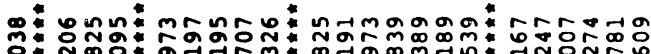

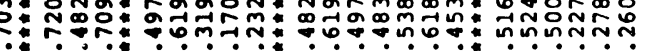

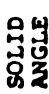

:

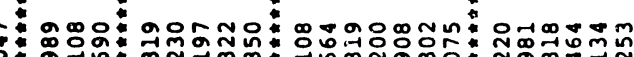
กิ่ :

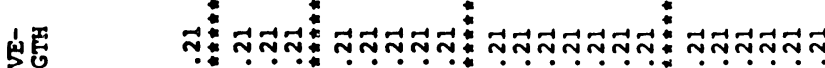
目
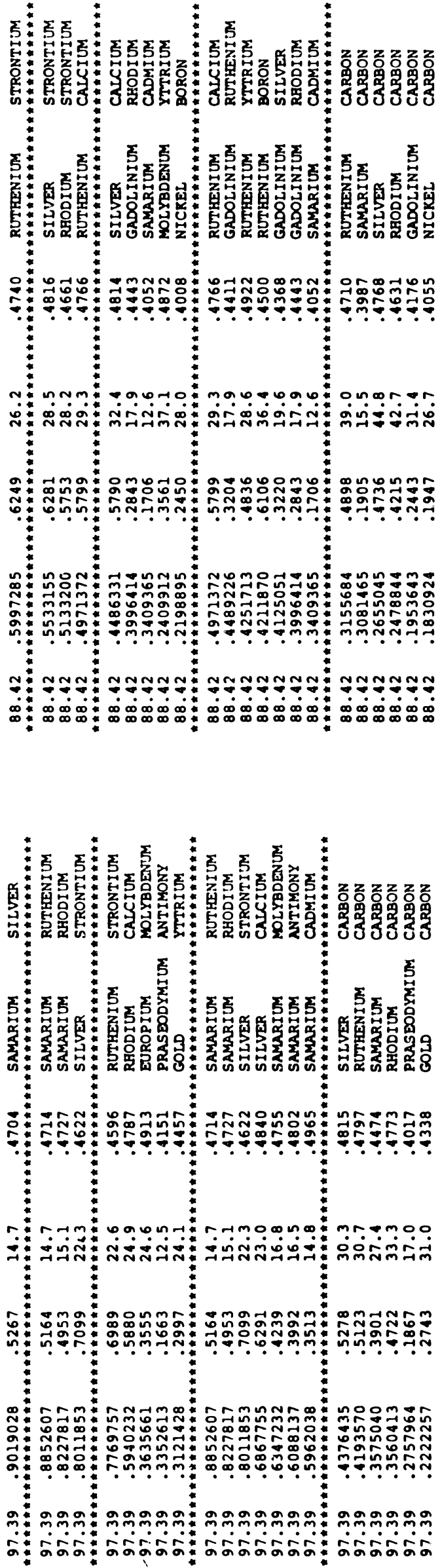


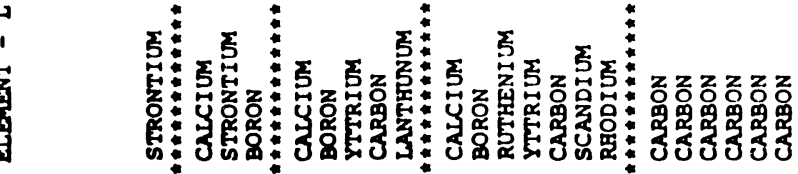

兽

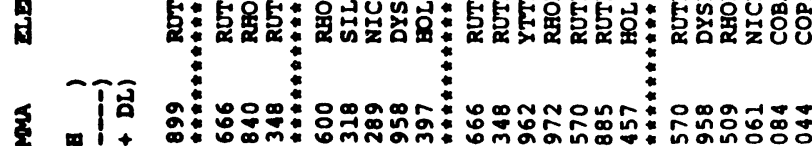

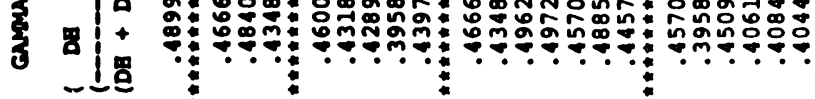

舲

4

锟竞

䞨<smiles>CC#CC=CC=C1CCCCC1</smiles>

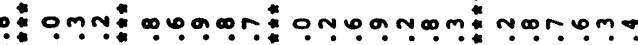

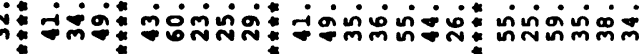

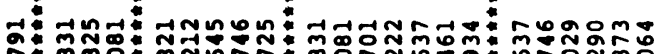

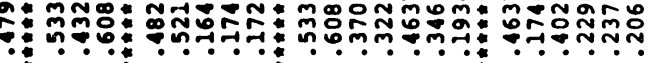

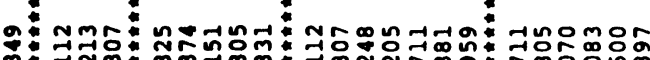

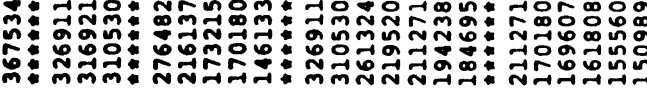

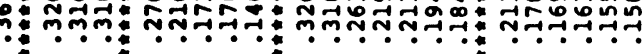
\% \%99 \%9990 9\%9\%9\%9 999999

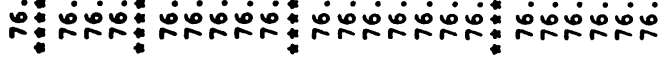

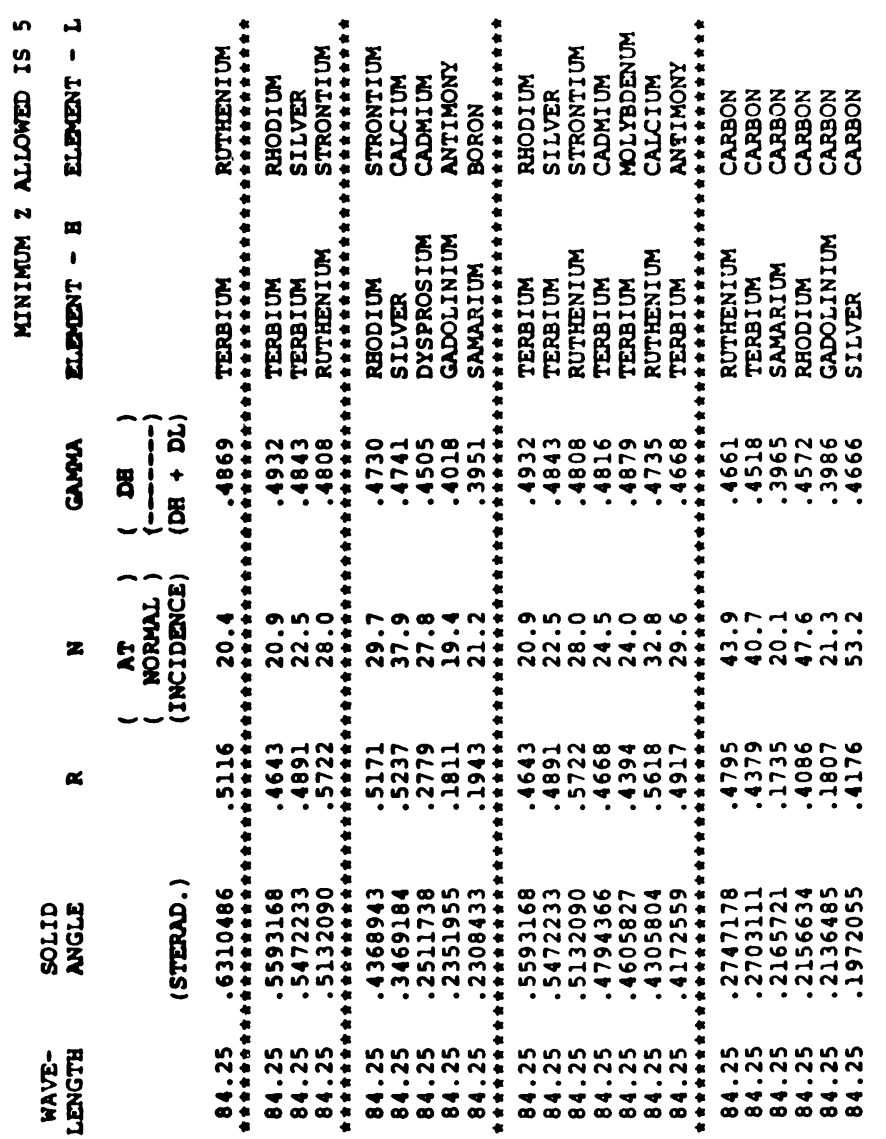

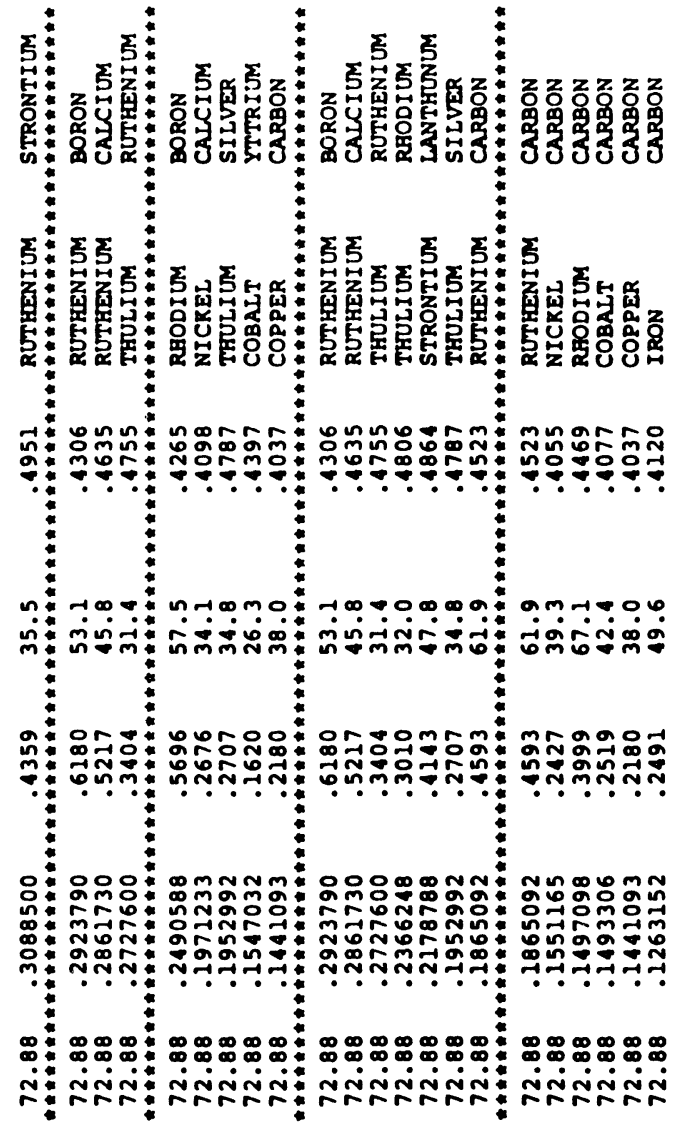

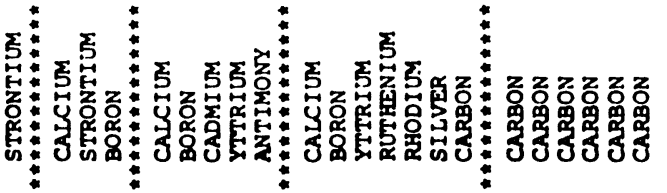
-

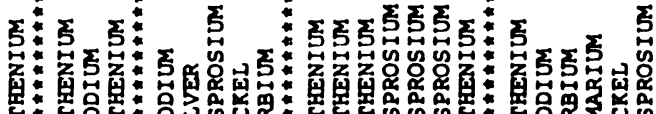
* : 1 年

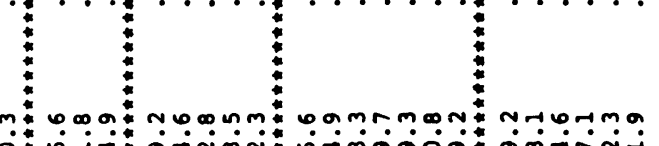

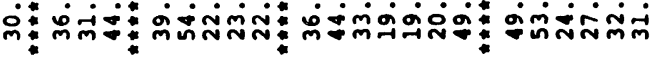
Don 倠 1
0
0 
告

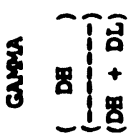

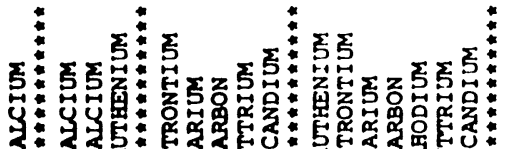

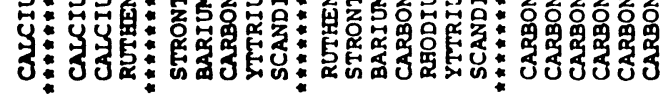

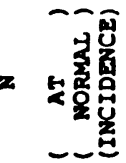

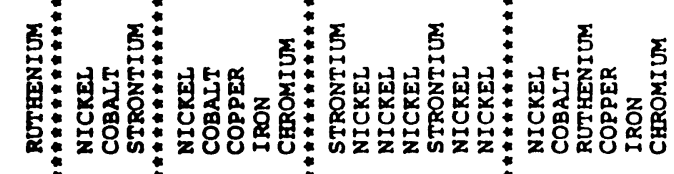

$\infty$

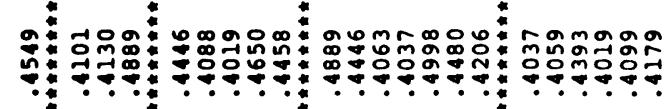

实

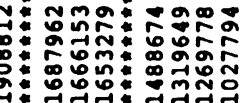

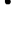

空总

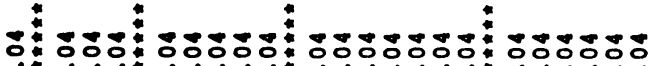

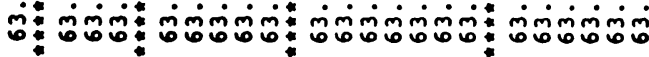

药

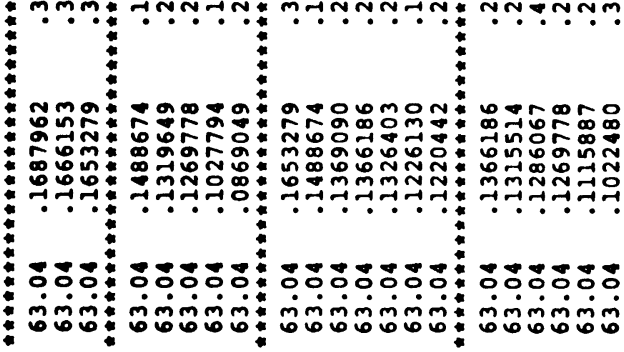

n

品立

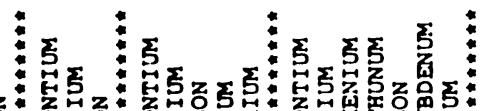
z

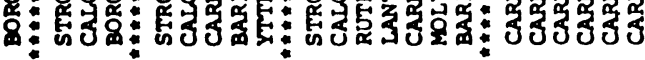
5

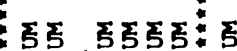

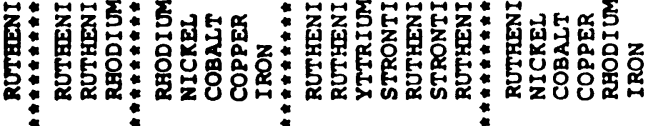
55555

कै

2

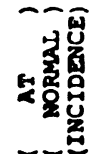

$\infty$

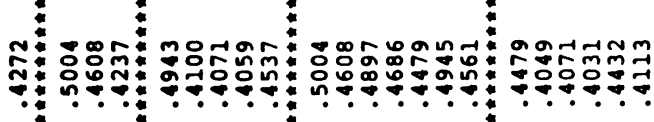

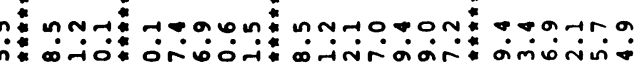
กิ๊ ิำกำ

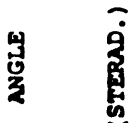

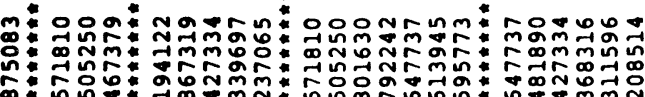

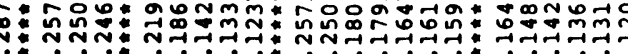
マ

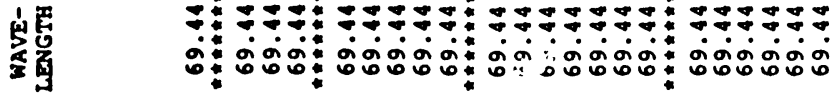

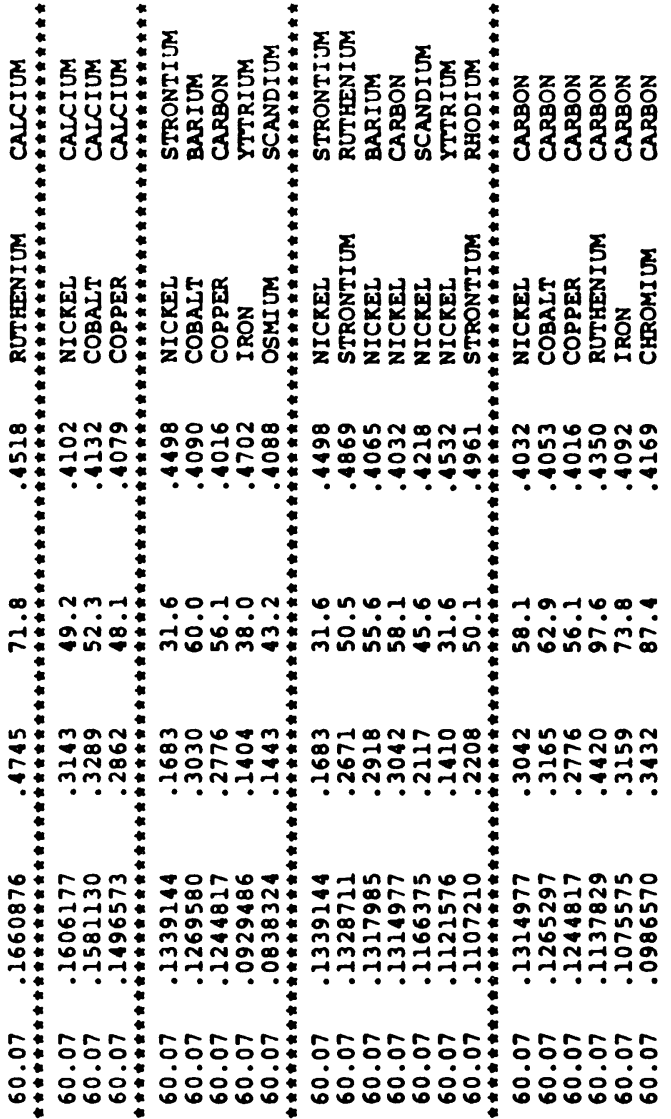

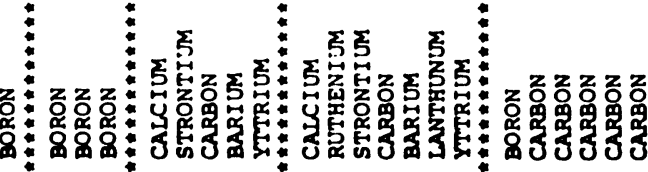

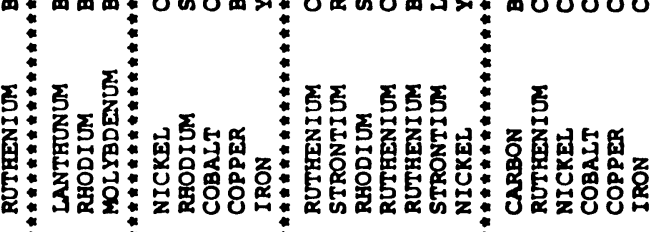

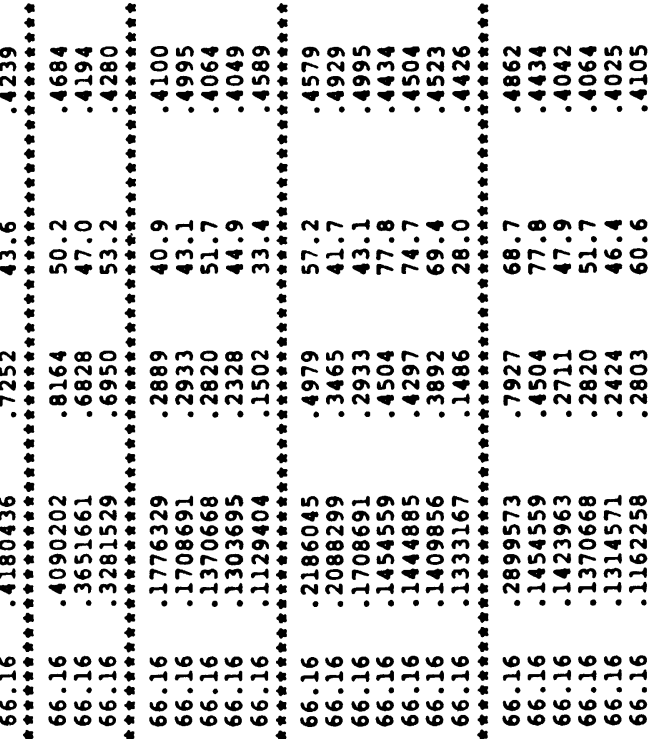



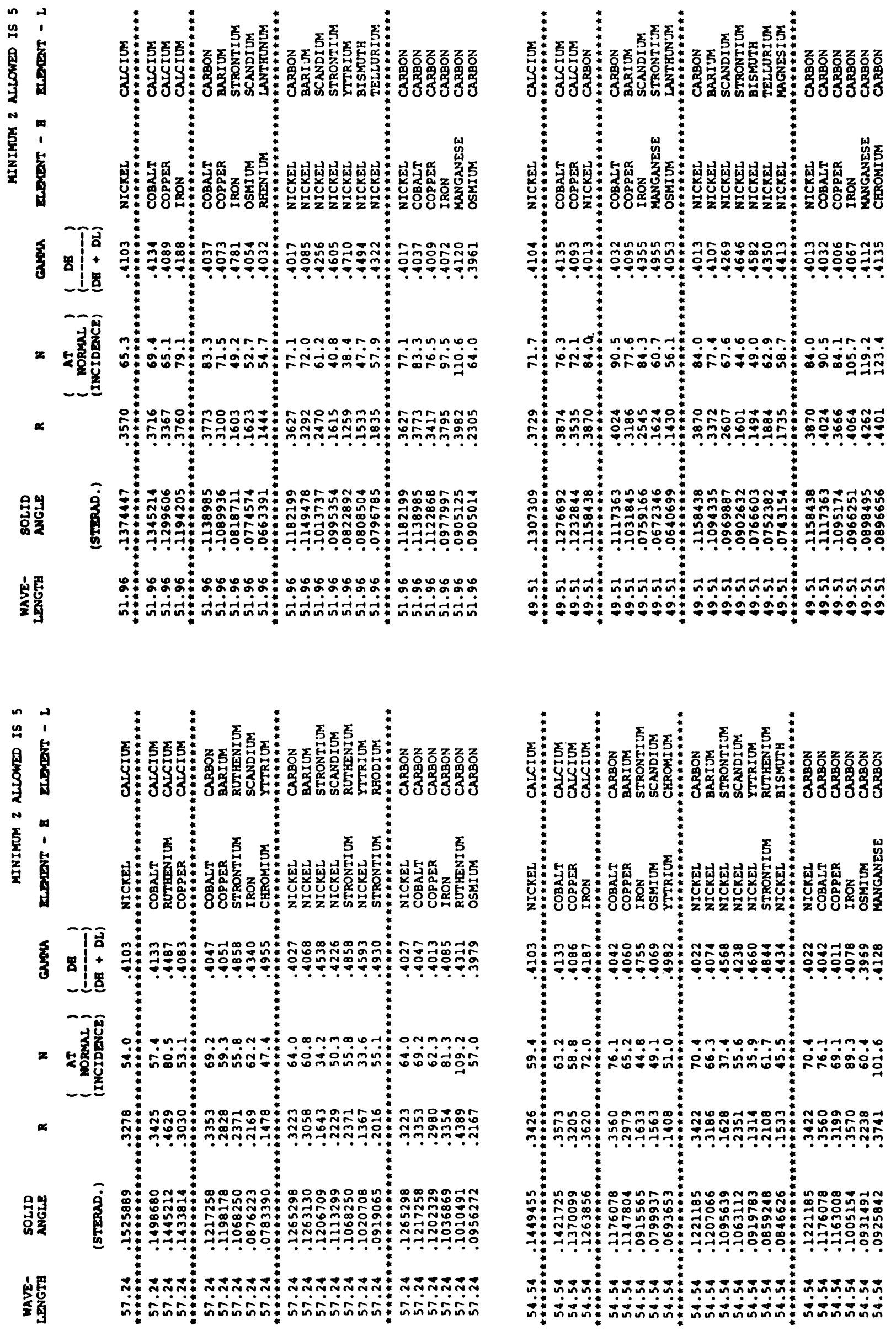

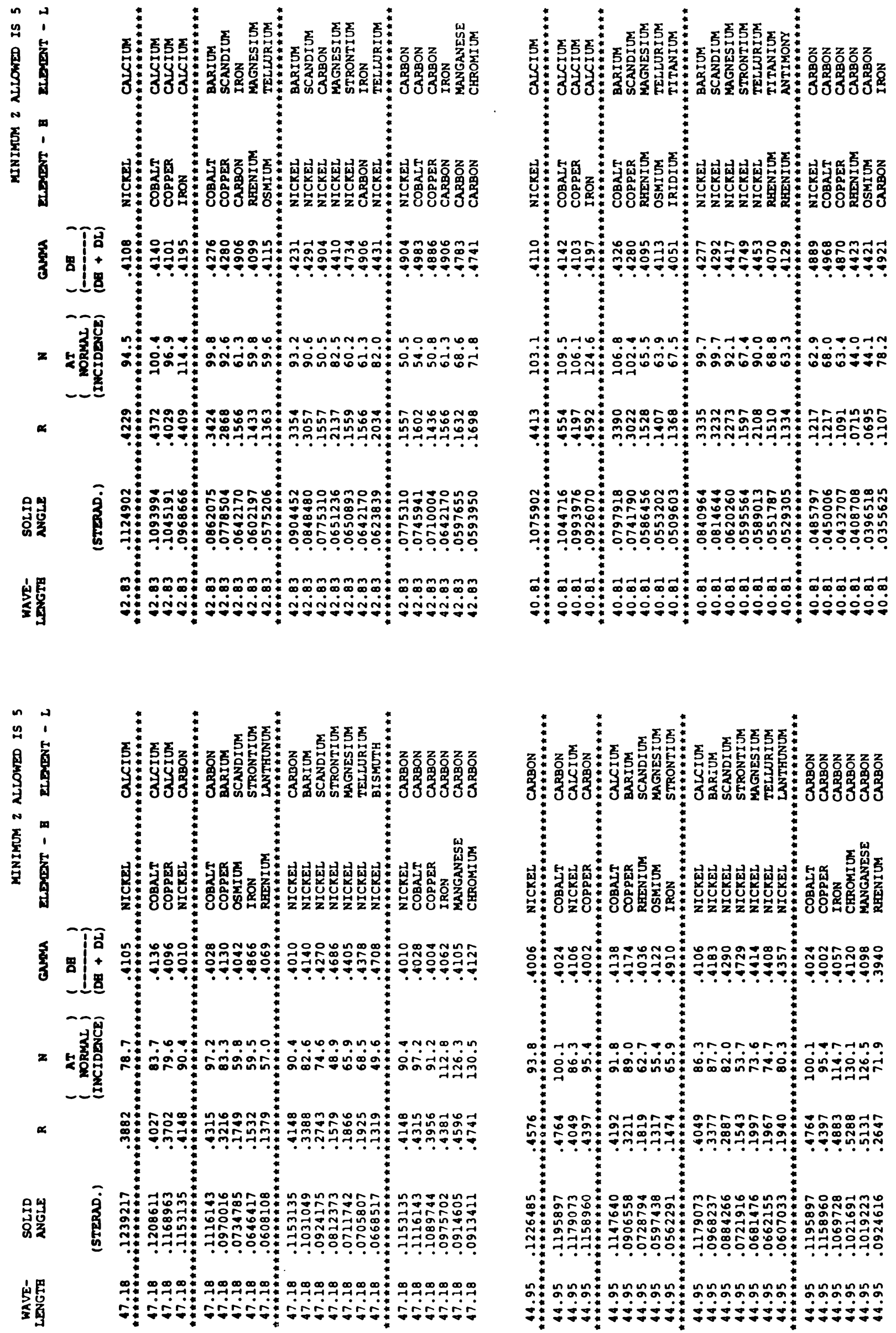


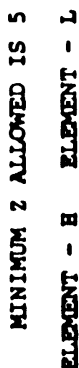

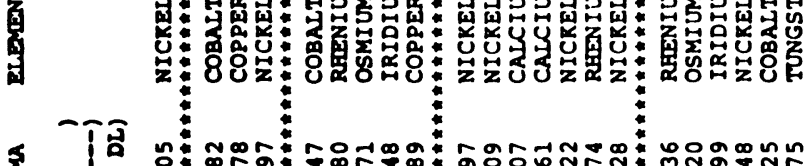

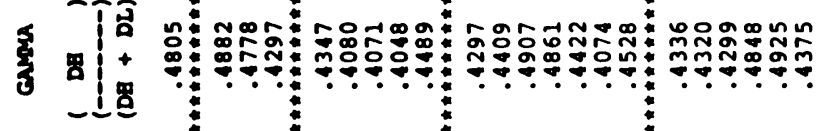

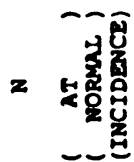

$\propto$

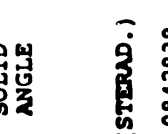

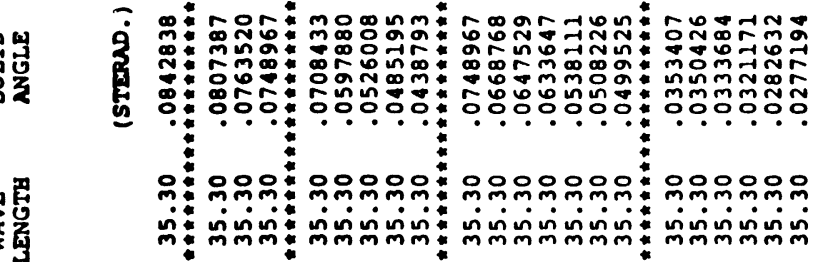

望

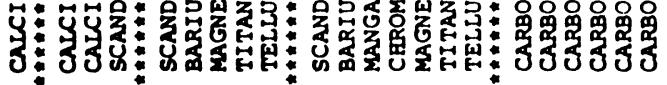

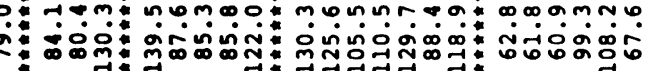

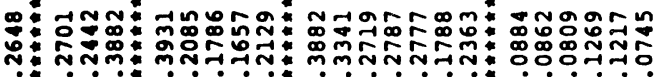
.

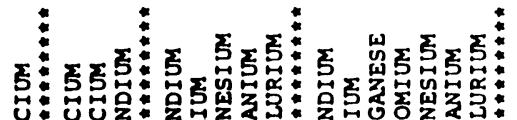

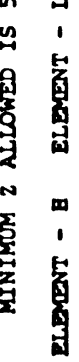

ริำ

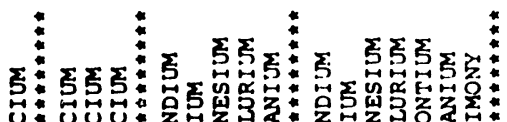

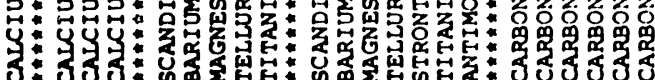

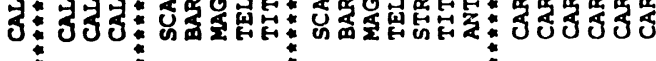

2

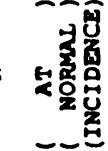

\section{果}

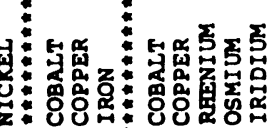

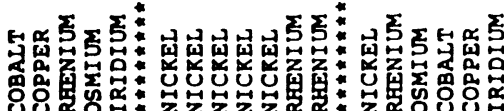

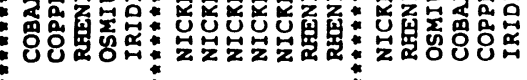

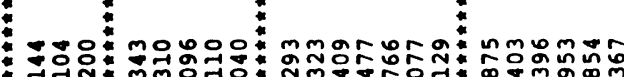

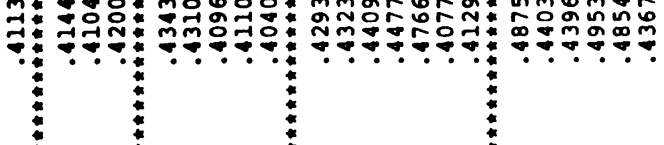

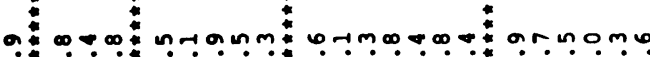

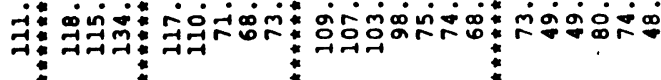

$\propto$

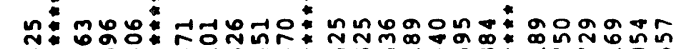

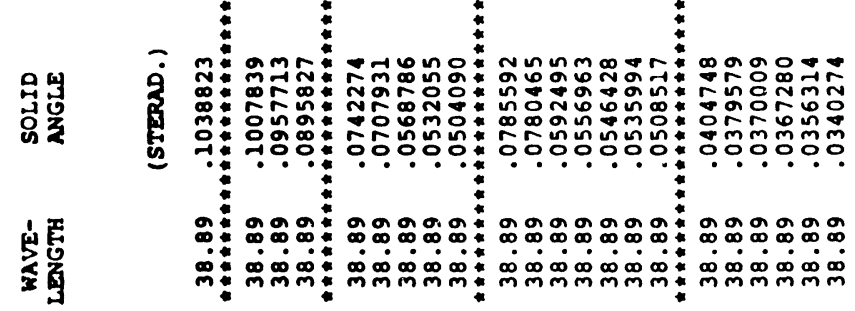

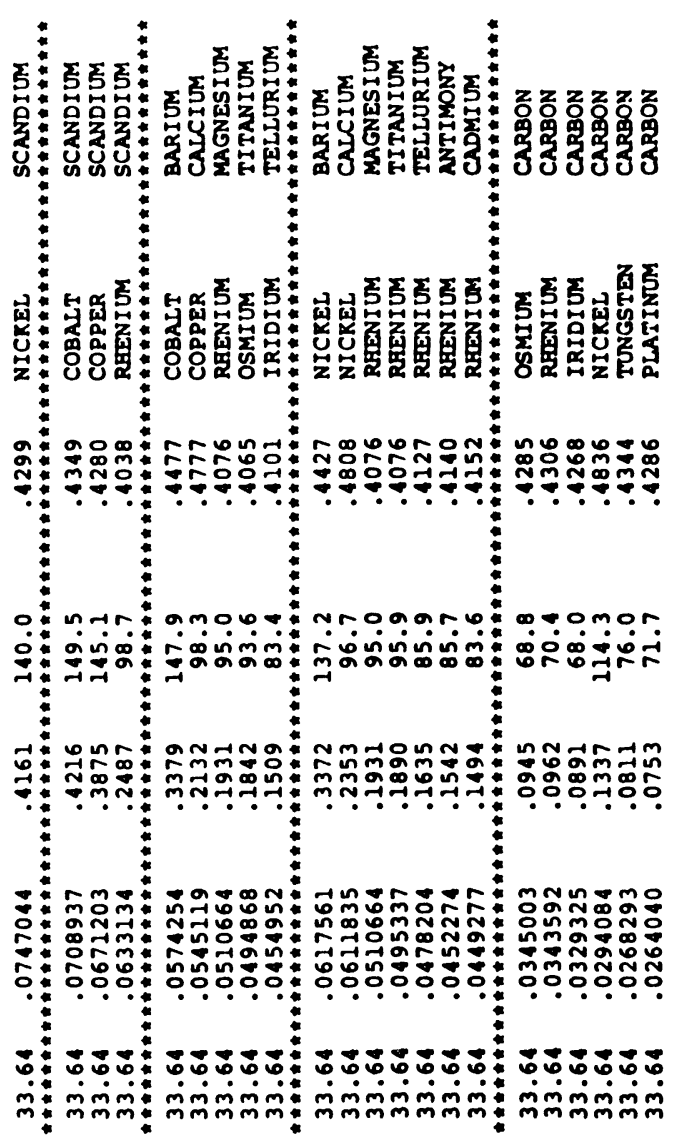

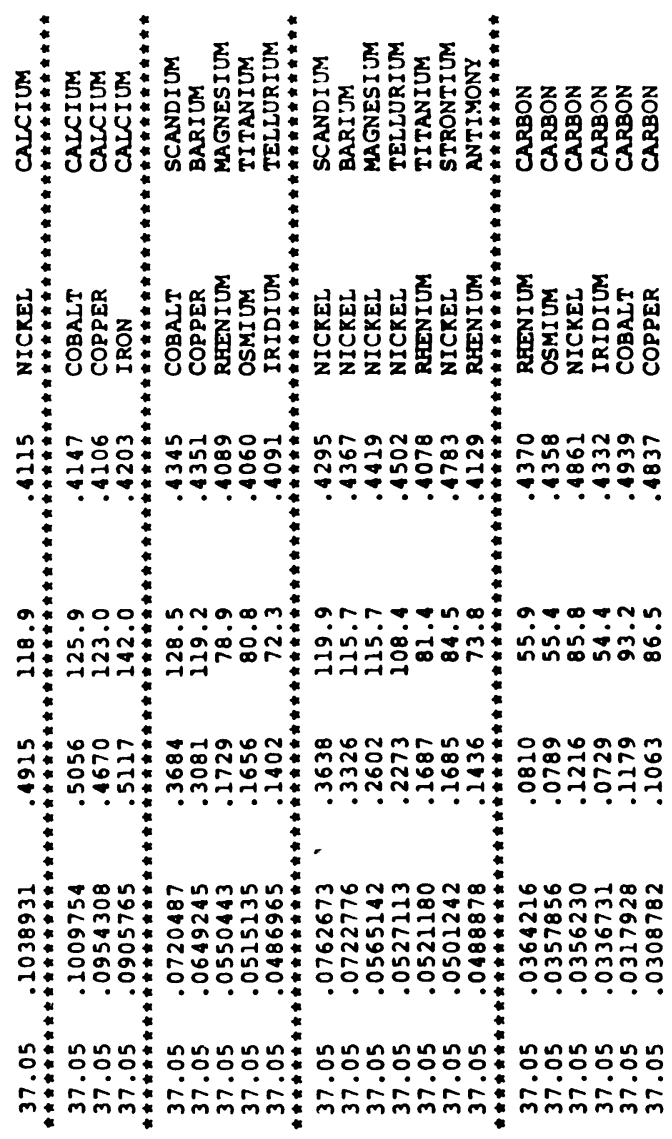



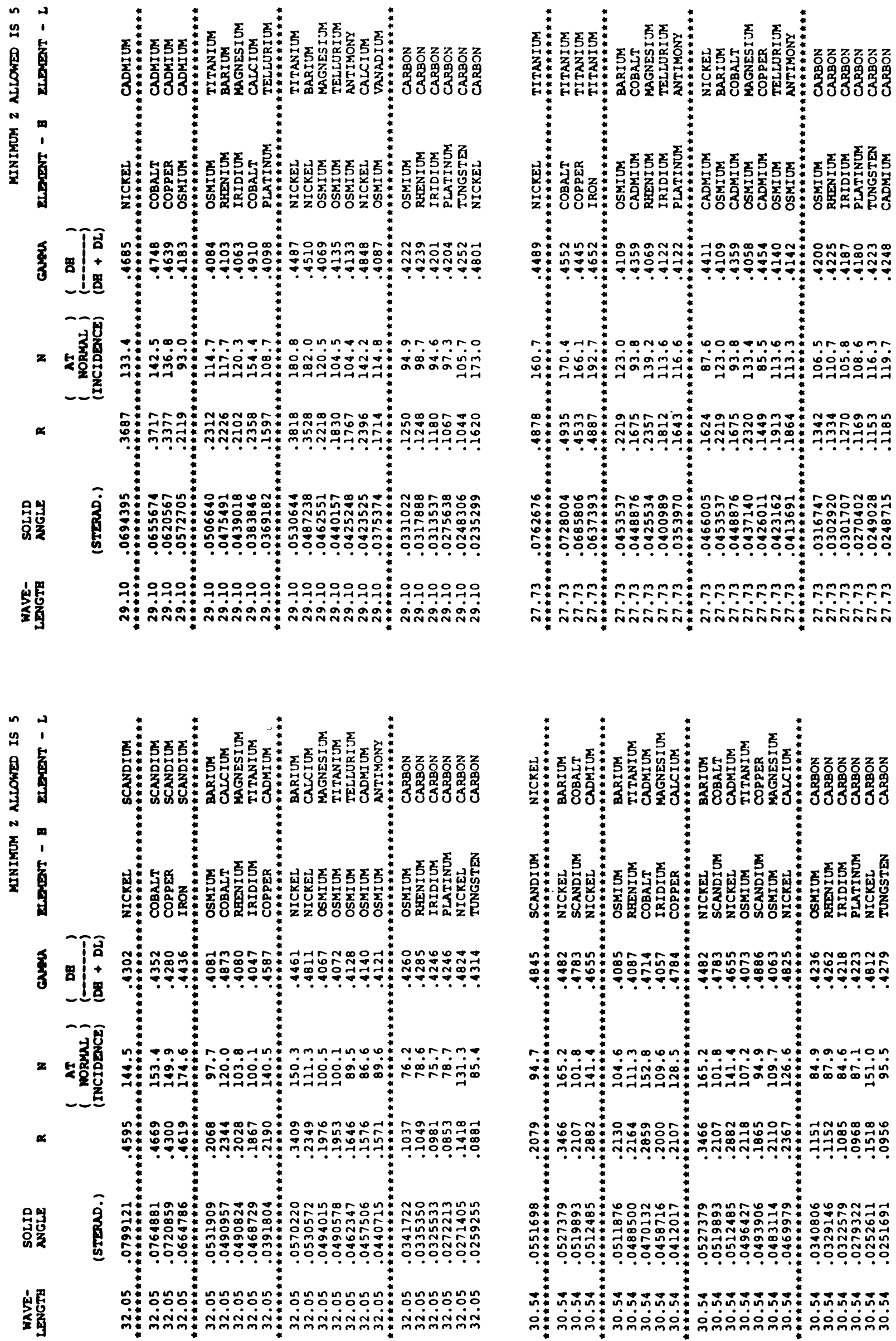


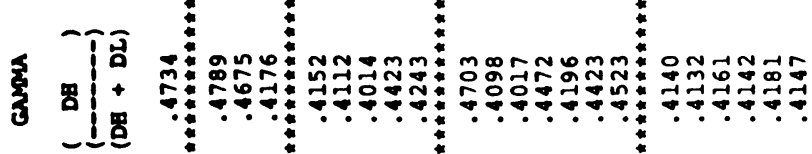

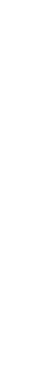

$=$

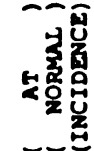

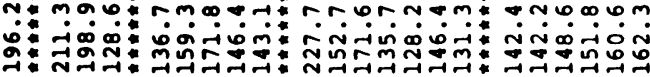

$\propto$

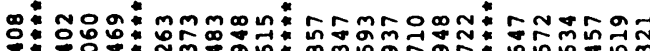

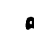

总出 究

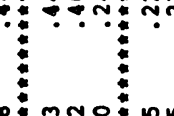

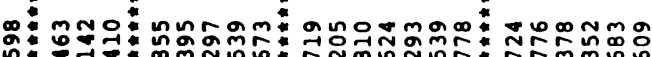

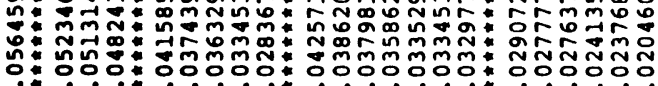

穿蛋

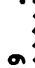

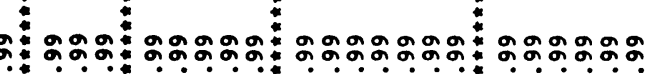

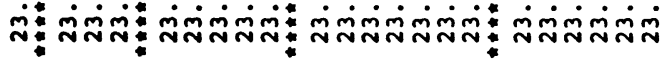

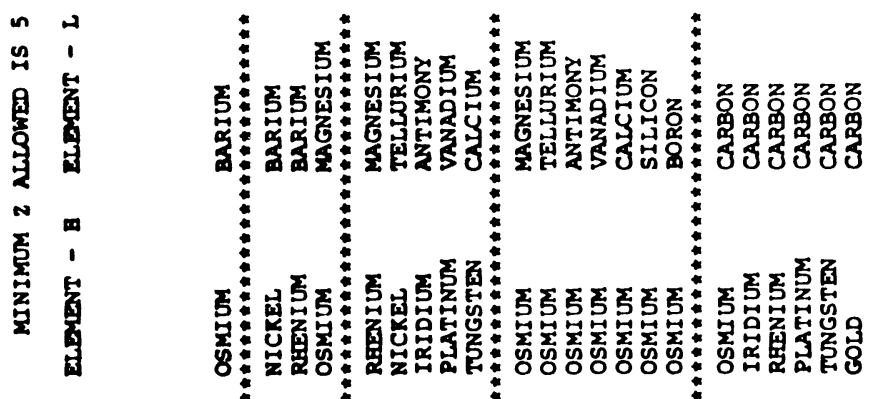

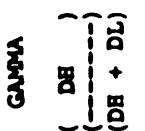

$=$

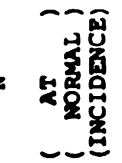

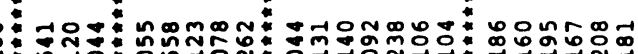

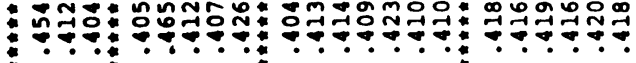

กำ

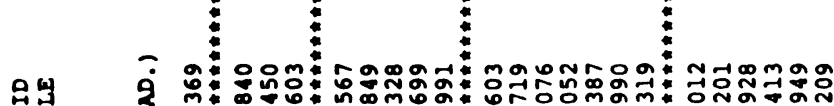

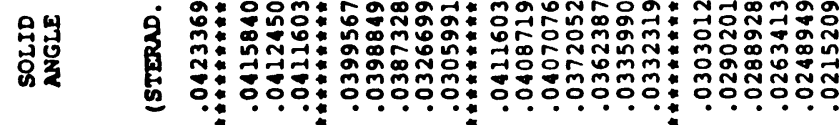

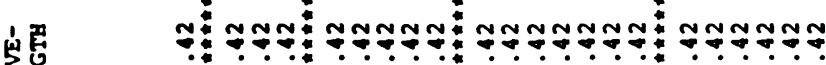

每

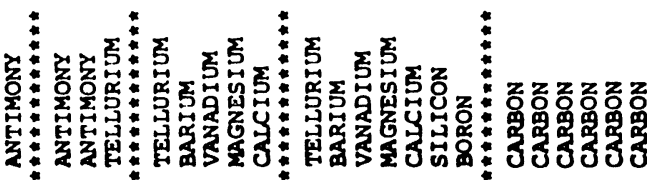

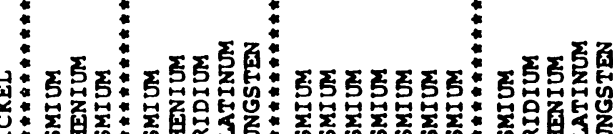

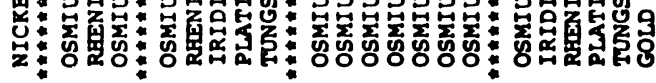

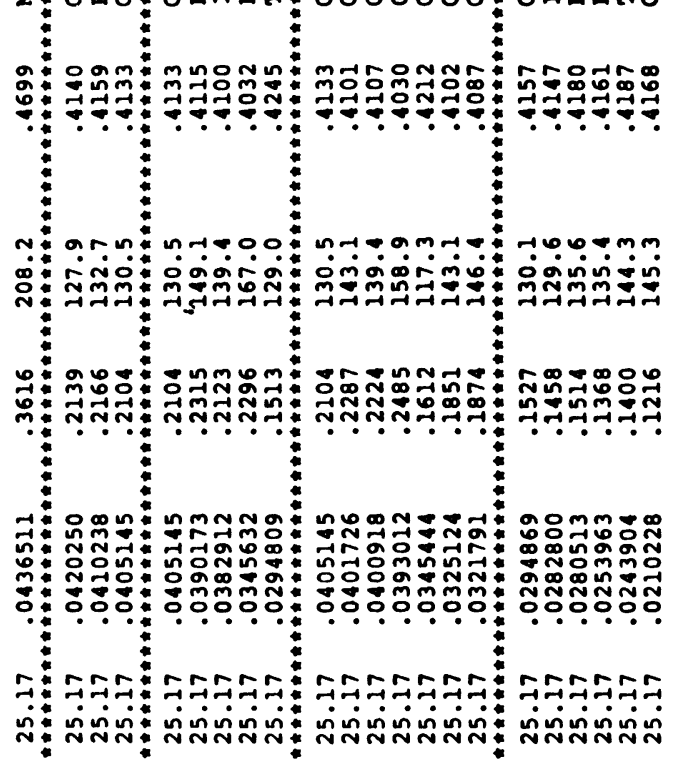



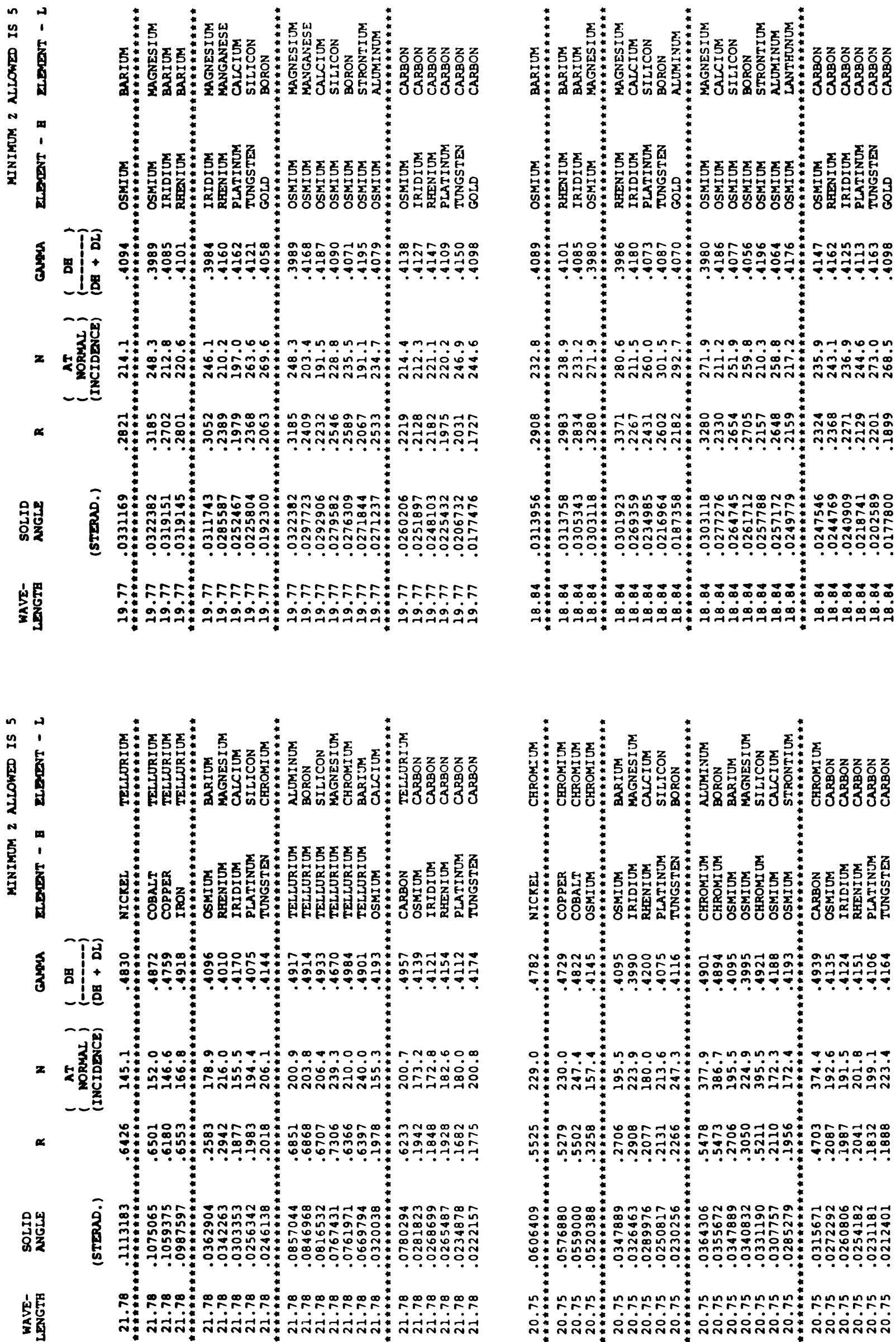

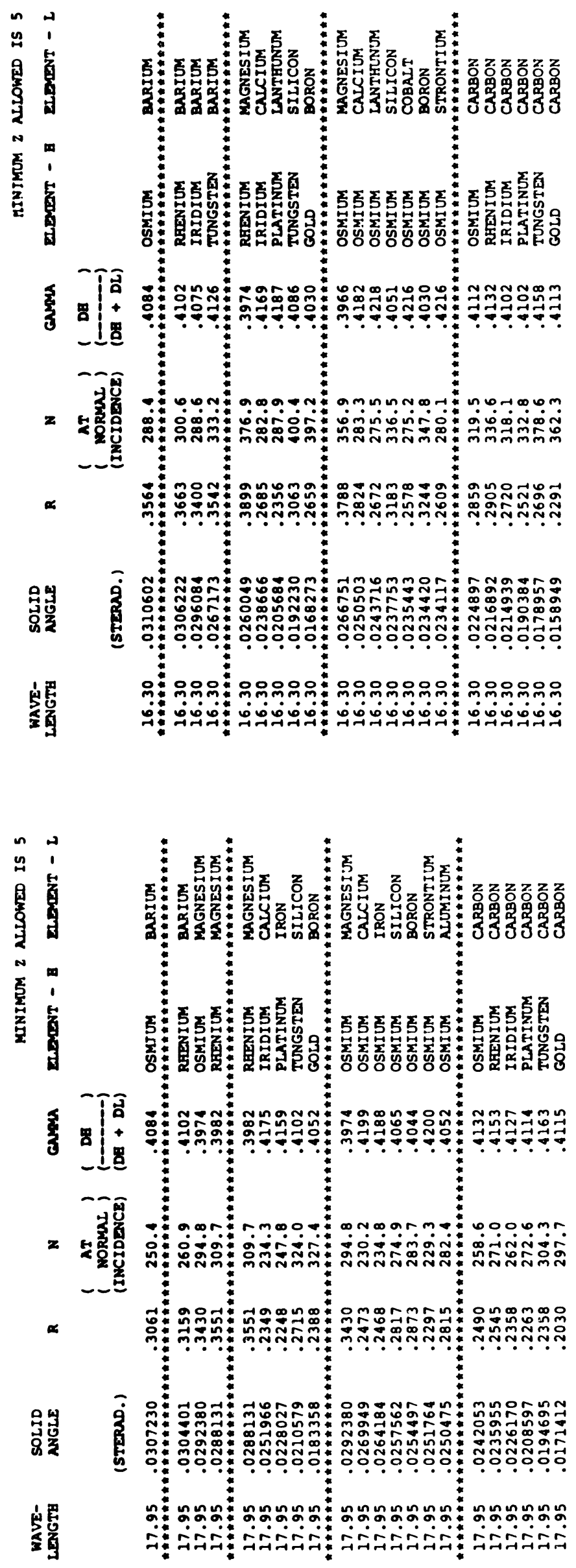
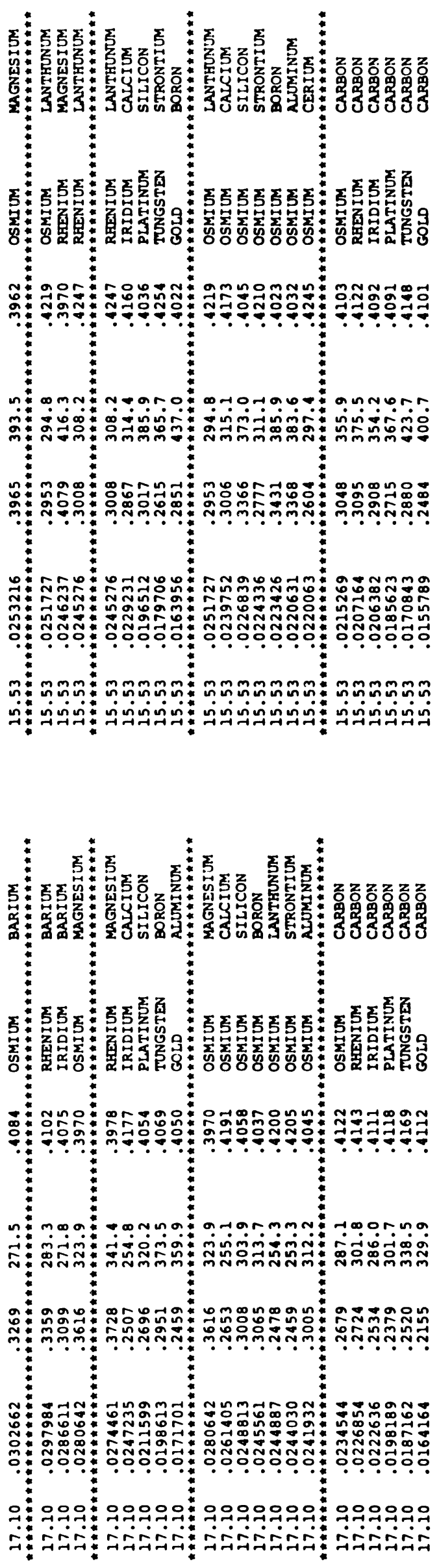

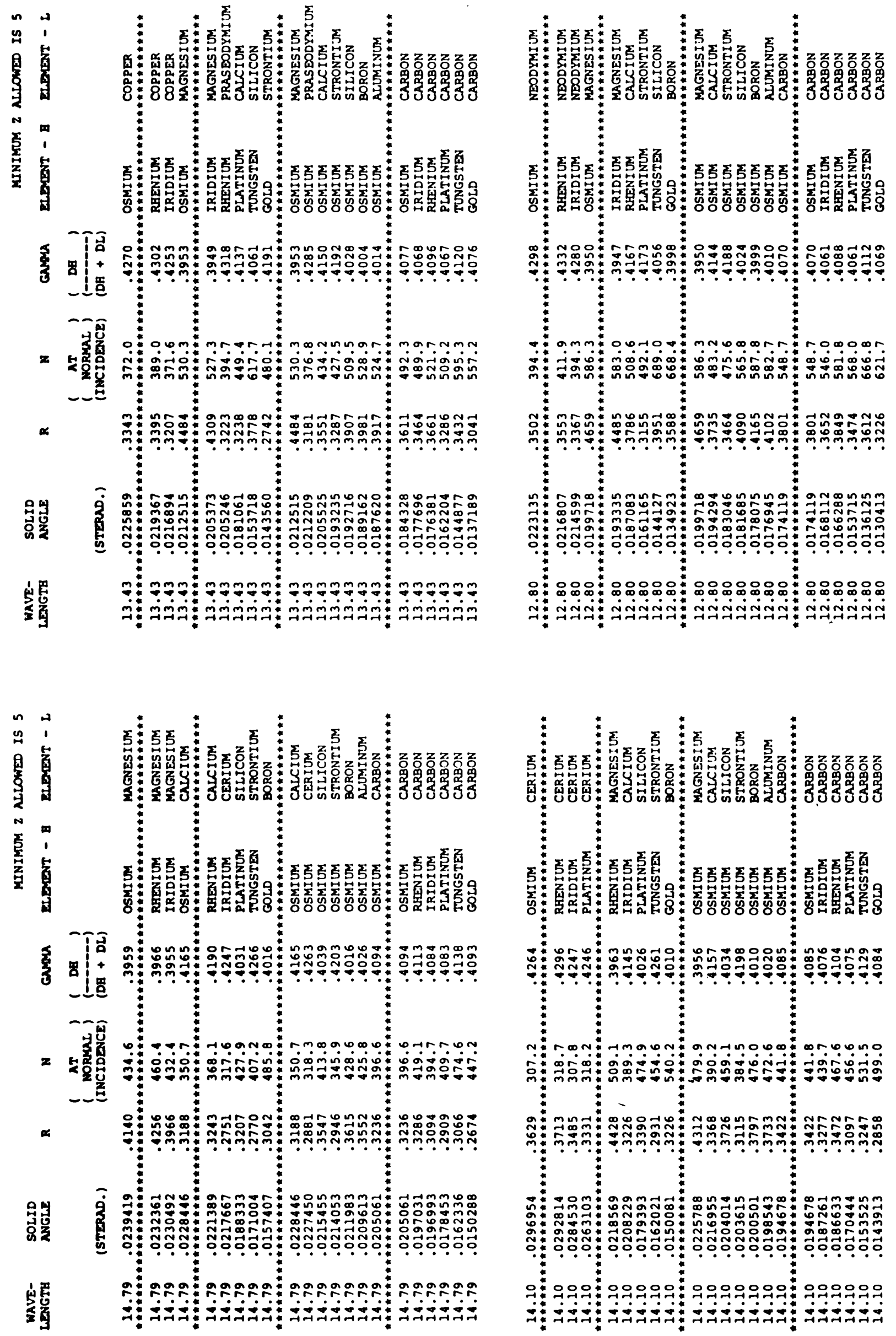


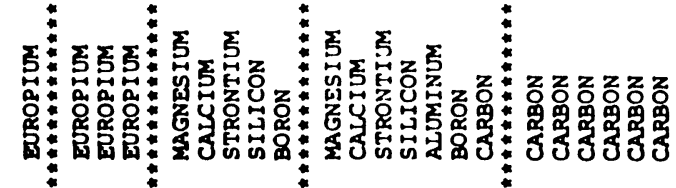

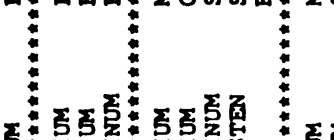

క

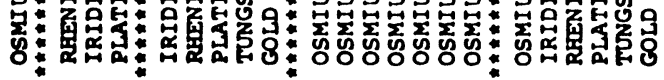

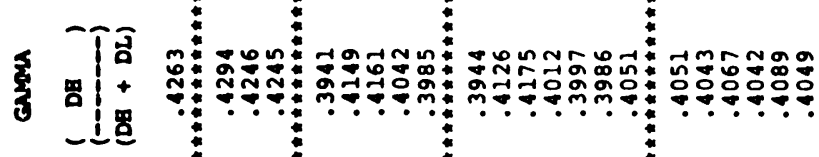

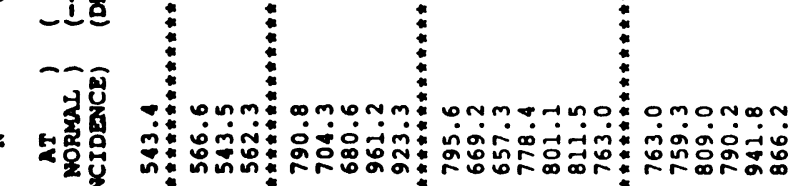

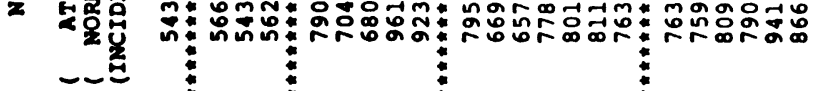

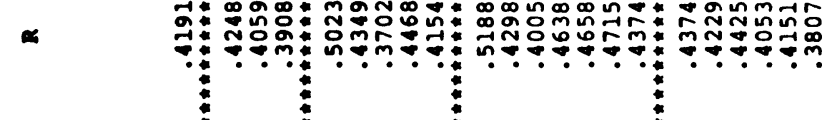

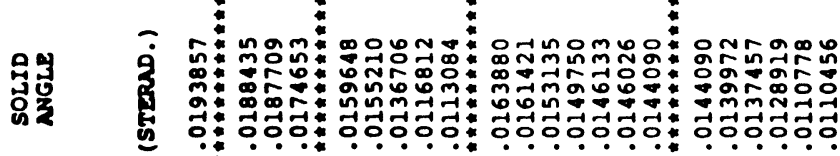

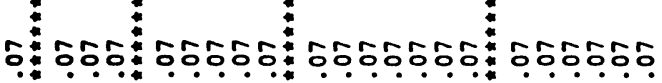

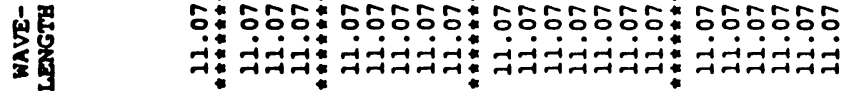

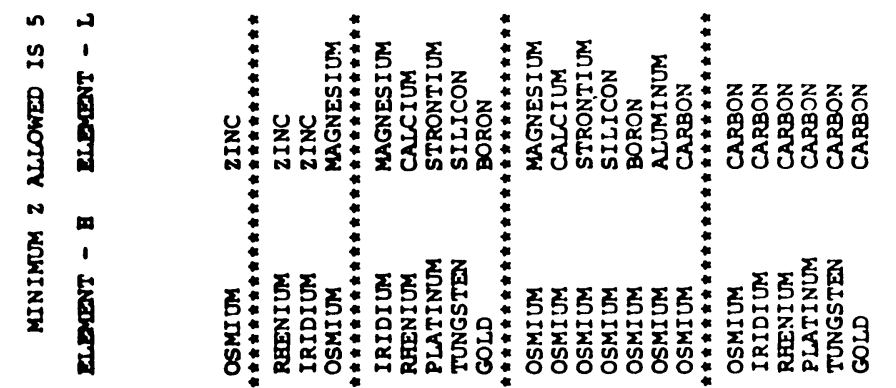

ริ

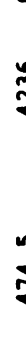

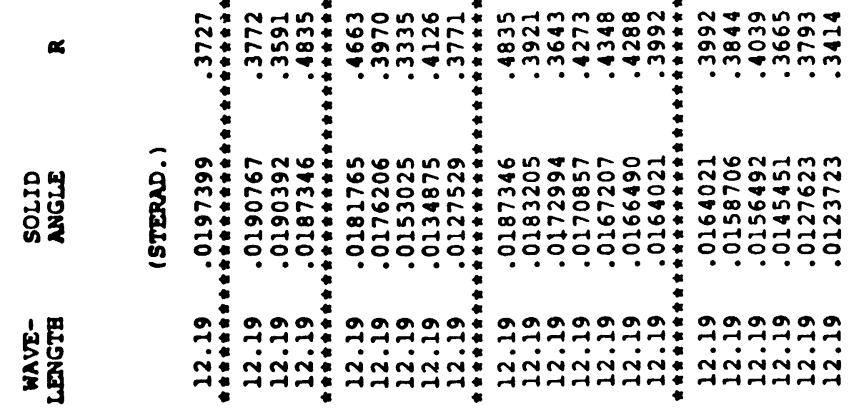

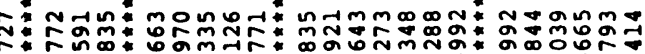

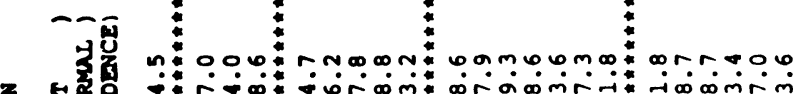

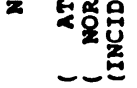

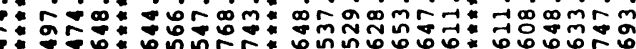

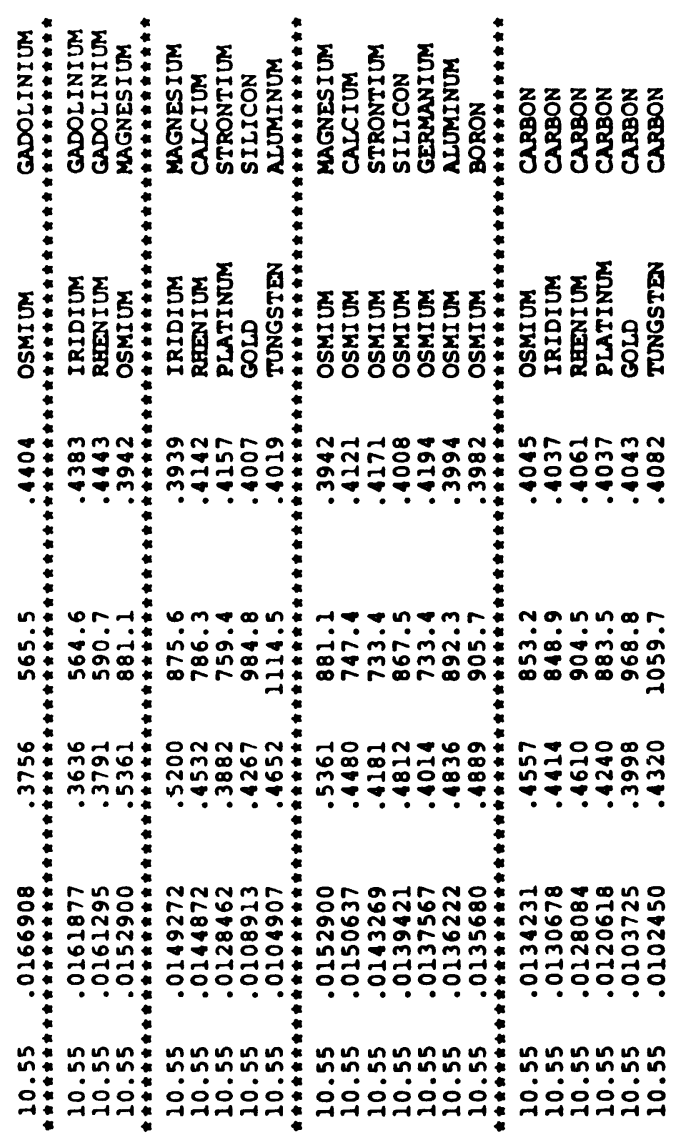

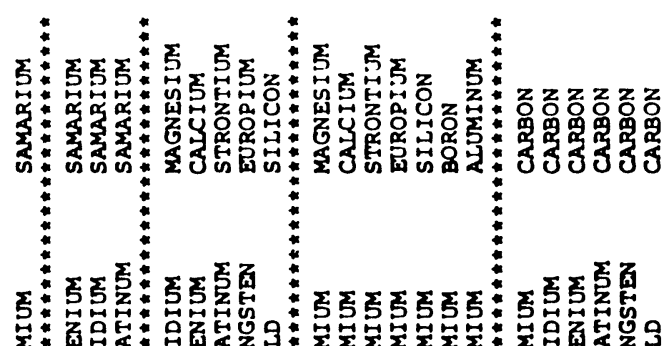

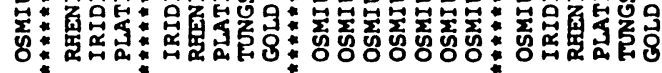
andanmom narmm-a

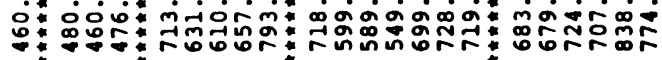

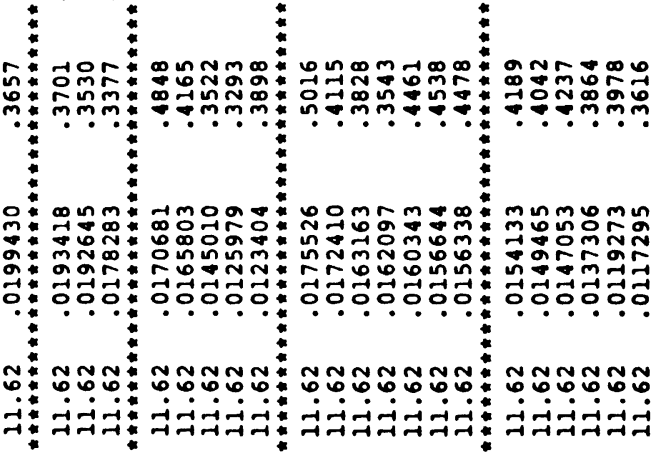


悬

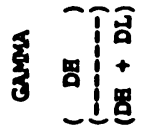

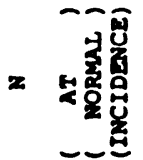

$\infty$

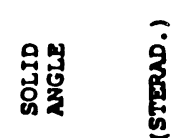

空罢

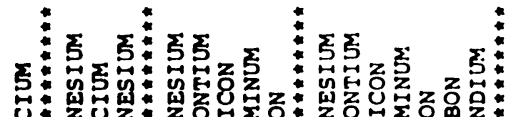

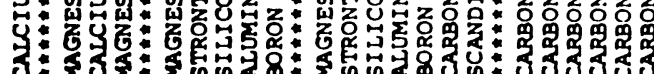

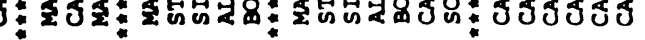

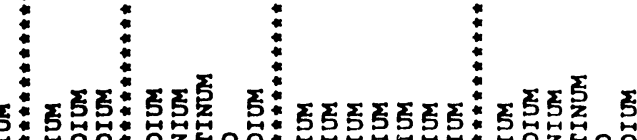

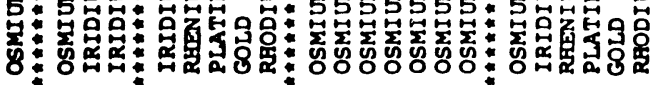

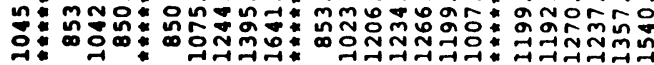
- $-0-\infty-\infty$

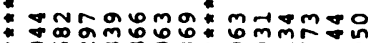

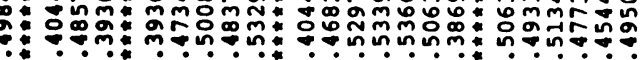

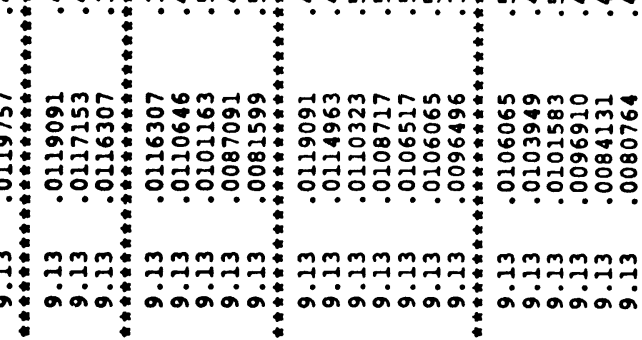

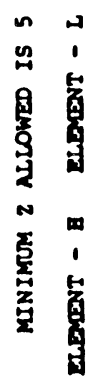

5

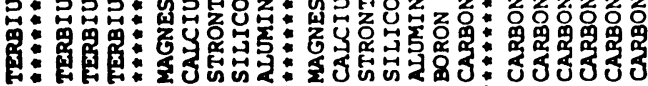<smiles>[3H]</smiles><smiles>C1CCCCC1</smiles>

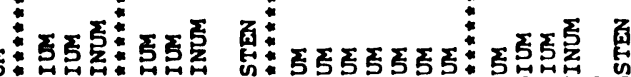
告

3

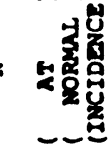

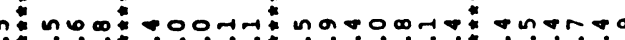

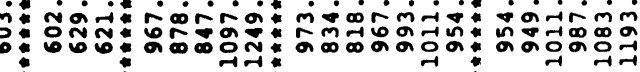

N

$\propto$

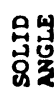

(3)

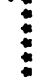

* 구울 กิธี - 0.00.0.0000.0.0.0.

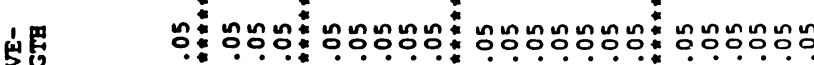

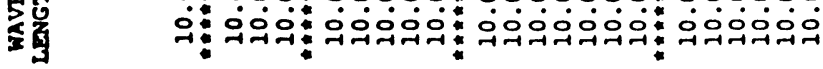

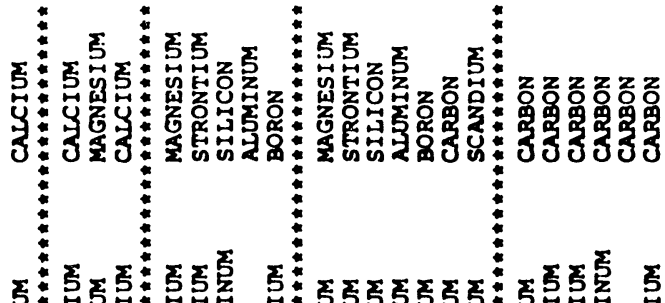

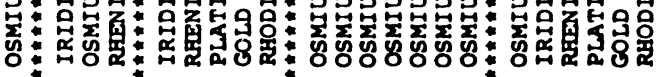

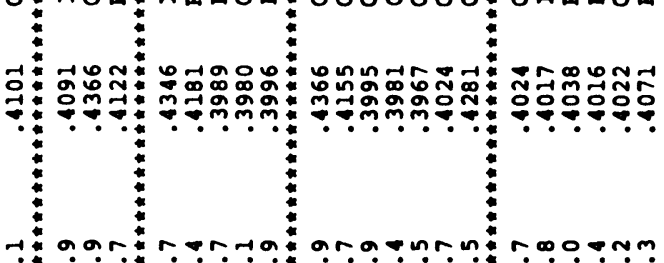

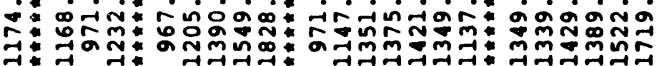

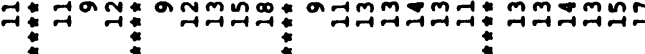

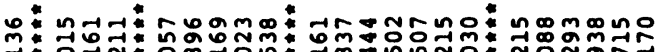
กี

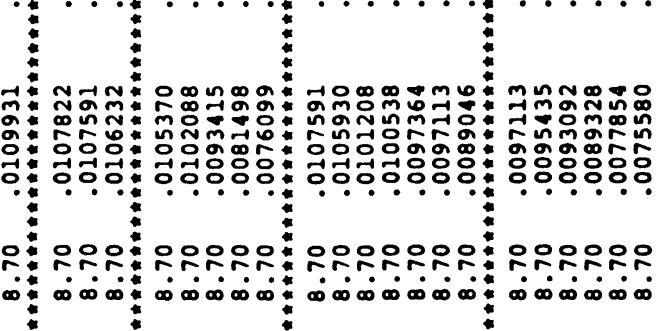

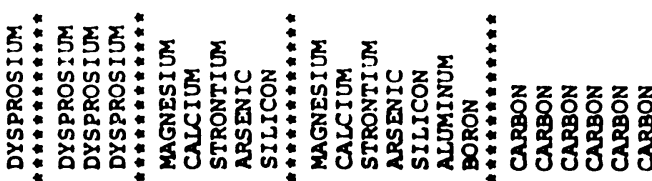

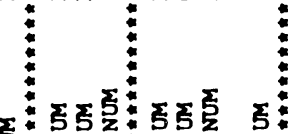

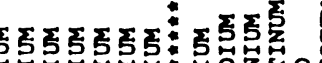

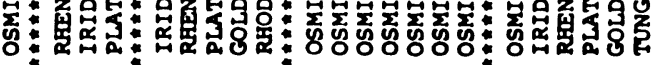
omm mnorn arm-nmm rarrm-

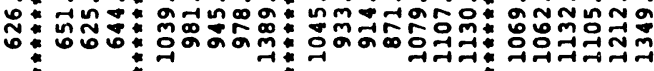

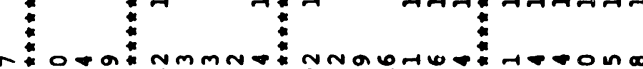
స

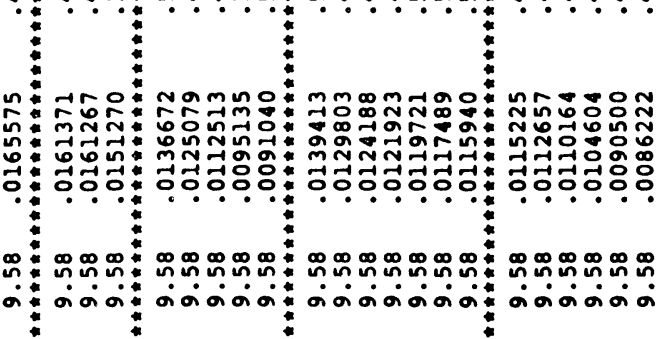




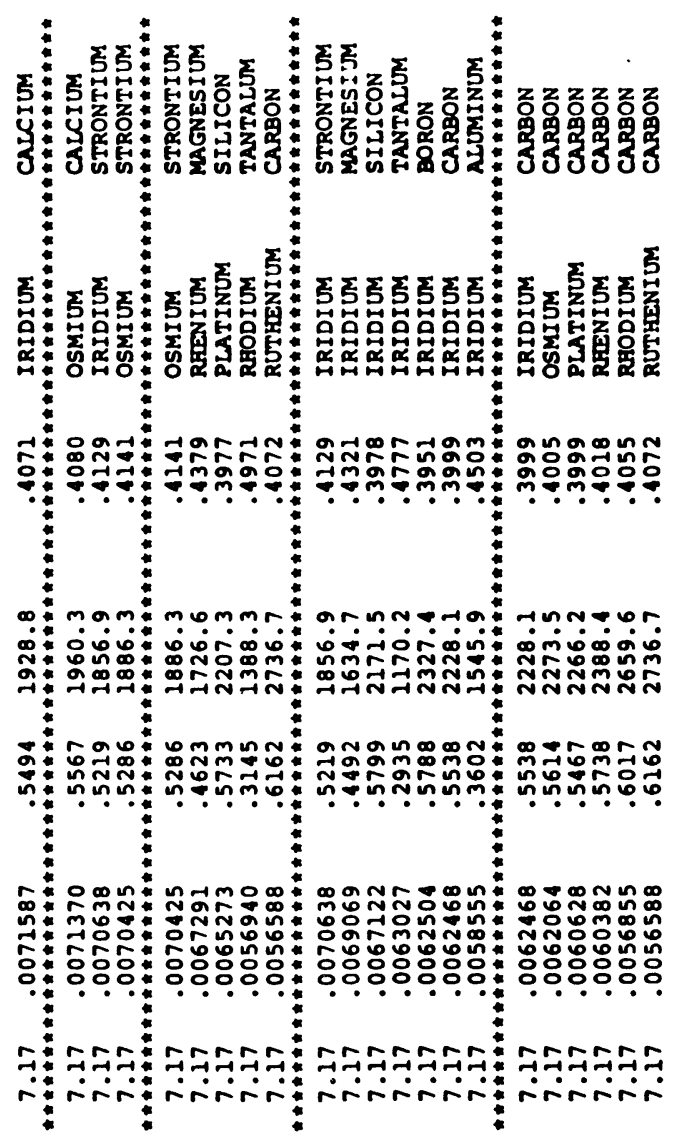

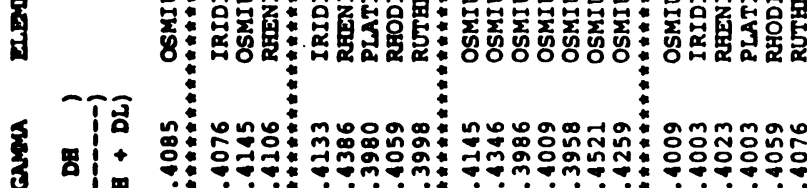

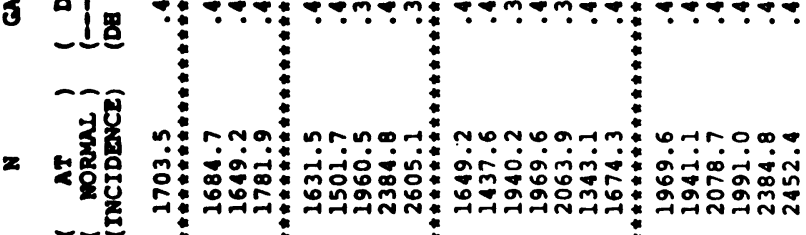
ำ

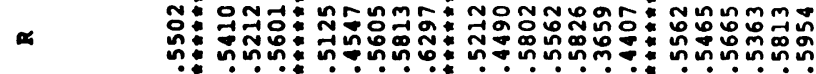

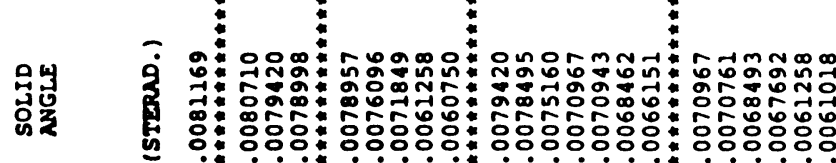

मू
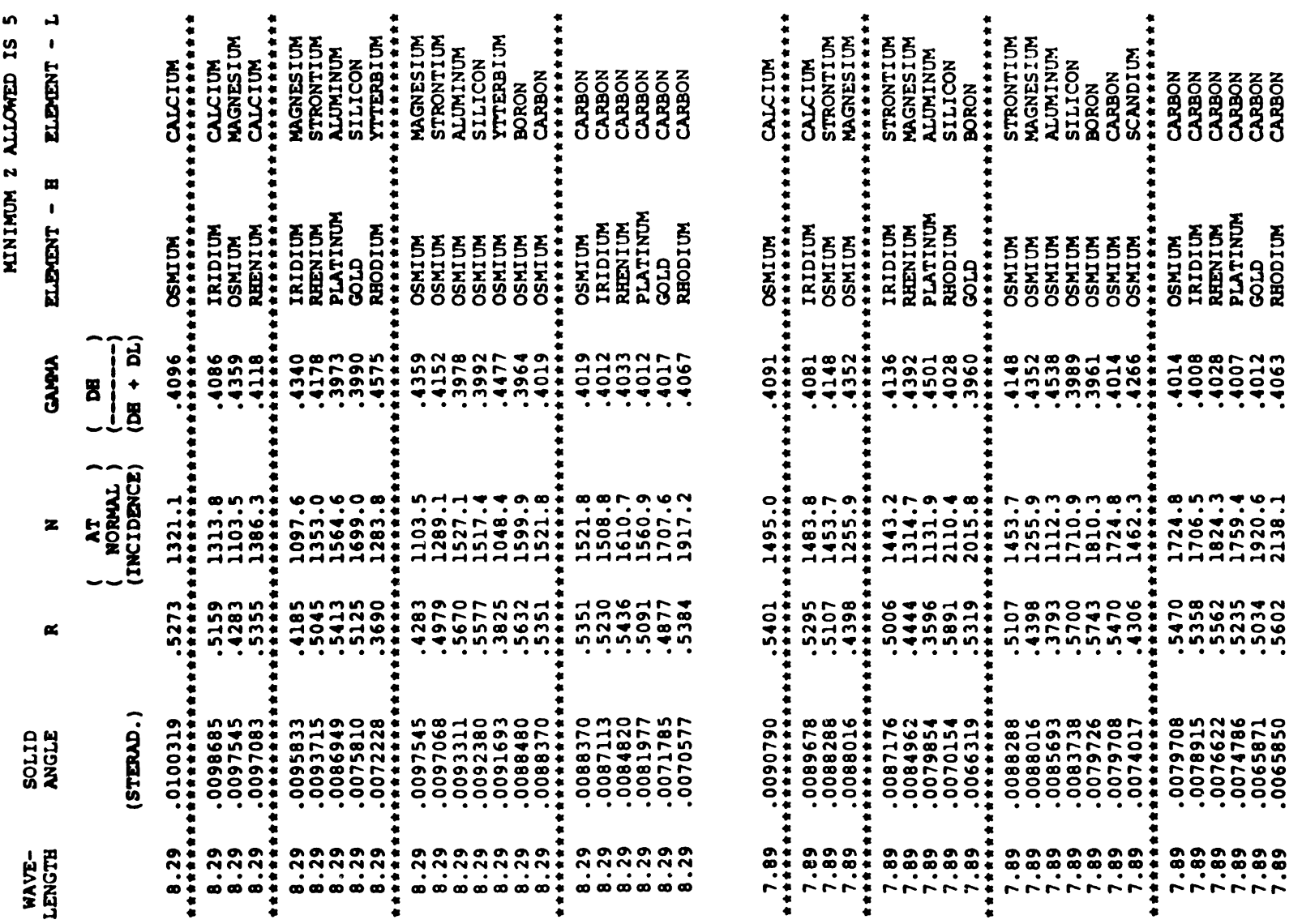


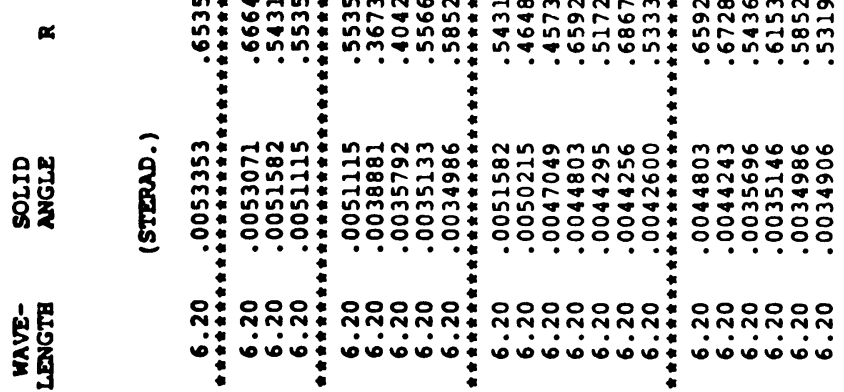

政
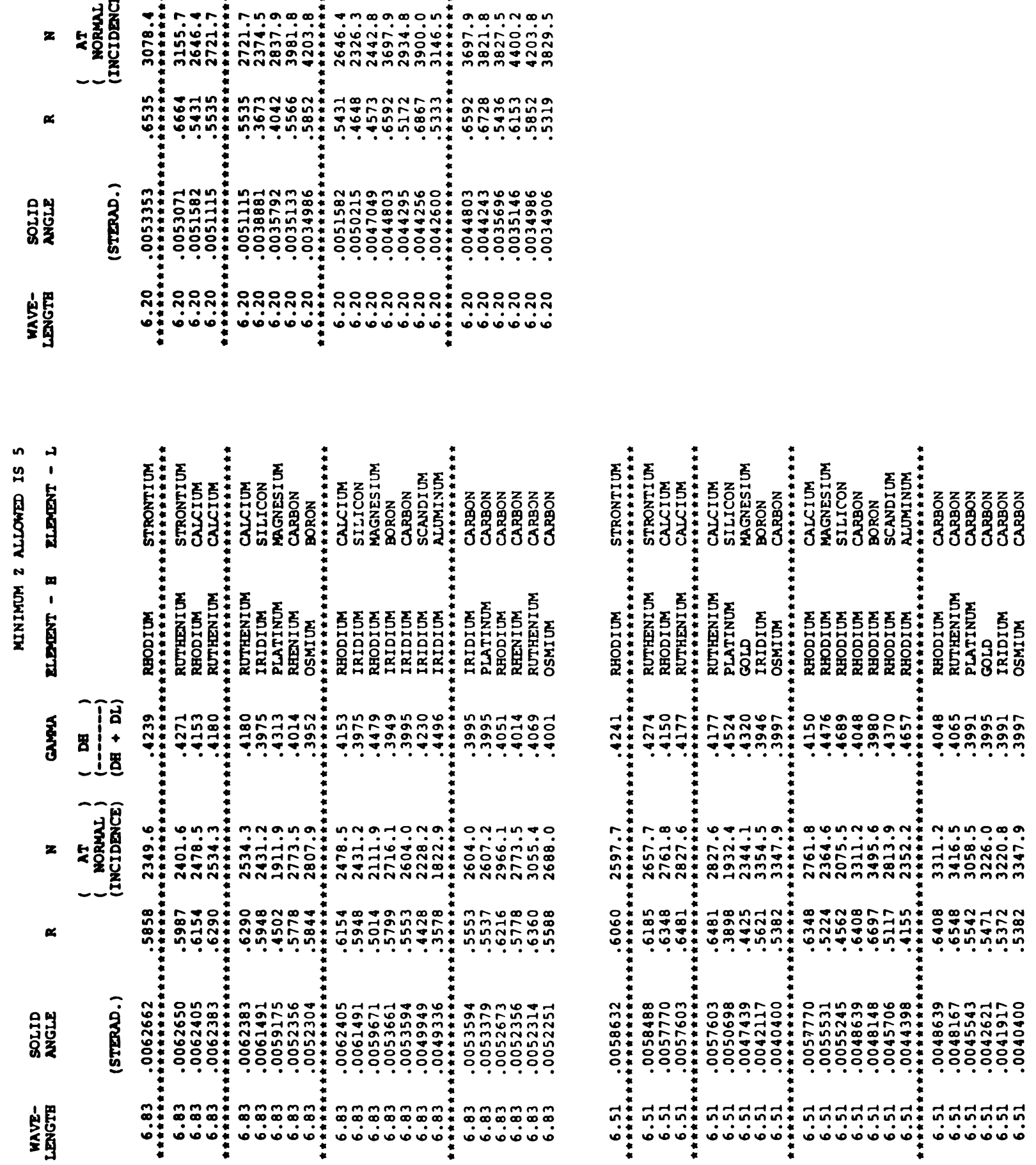


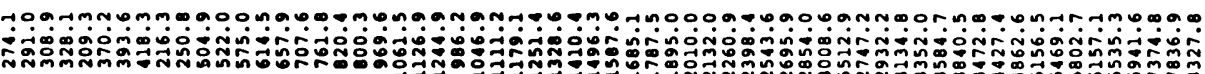
ヘ

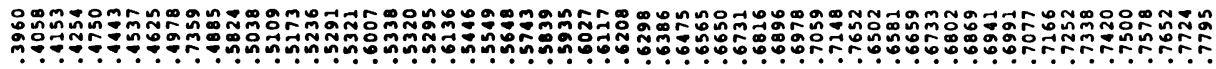

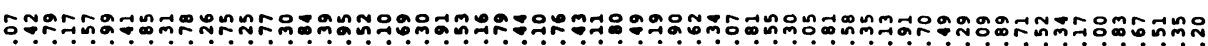

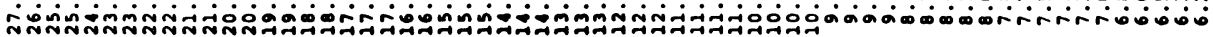

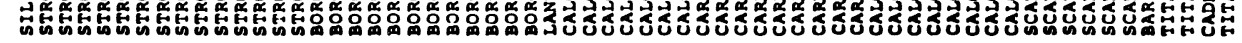

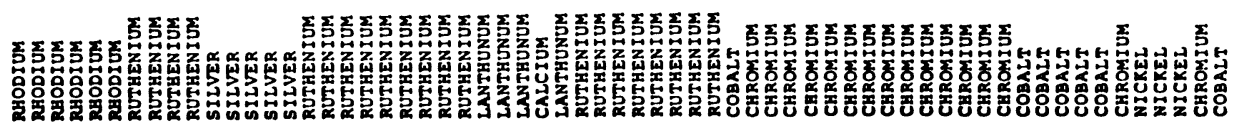

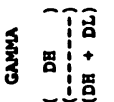

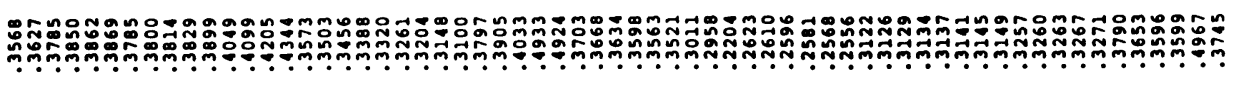

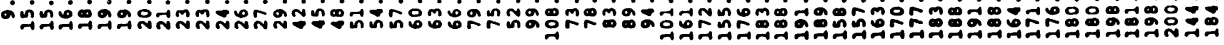

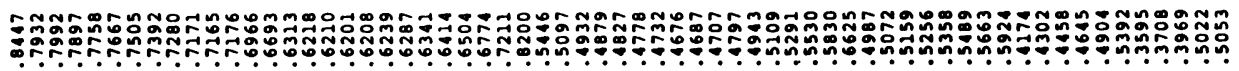

